\title{
Experimental and numerical heat transfer analysis of heat-pipe- based CPU coolers and performance optimization methodology
}

\author{
Matic Može*, Aljaž Nemanič, Primož Poredoš \\ Faculty of Mechanical Engineering, University of Ljubljana, Aškerčeva 6, 1000 Ljubljana,
} Slovenia

*matic.moze@fs.uni-lj.si, +3861 4771309
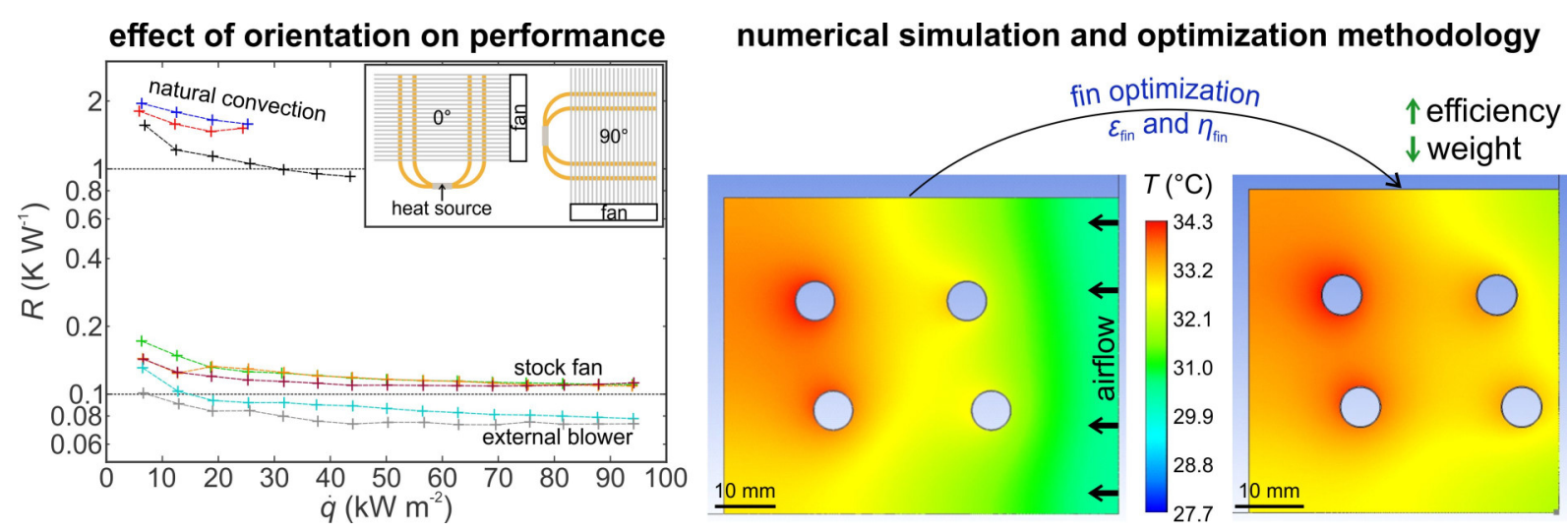


\begin{abstract}
This paper presents an experimental and numerical heat transfer analysis of heat-pipe-based CPU coolers and a performance optimization methodology. The first part of the study focuses on the performance of two commercial HP-based CPU coolers under inclination angles of $0^{\circ}$, $90^{\circ}$ and $180^{\circ}$. The results show that the $90^{\circ}$ orientation provides the best thermal performance. The influence of heat pipe orientation on the performance of the entire system is obscured due to the much higher thermal resistance on the air-side of the cooler. A fourfold increase in air volumetric flow rate has only a minor effect on the cooling performance enhancement with a reduction of the thermal resistance from $0.11 \mathrm{~K} \mathrm{~W}^{-1}$ to $0.074 \mathrm{~K} \mathrm{~W}^{-1}$ at the highest heating power. In the second part of the study, heat transfer numerical simulations of the finned part of a cooler were performed and validated using experimental results. The output of the simulation is a 2-D temperature field, which is used as an input for the optimization methodology based on fin effectiveness and fin efficiency. Optimizing the fin geometry by removing unnecessary material yielded a $23 \%$ increase of the fin efficiency and decreased the weight of a fin by approx. $30 \%$, proving the usefulness of the proposed methodology, which helps reduce costs, weight and development time of finned HP-based coolers.
\end{abstract}

Keywords: thermal management; heat exchangers; heat pipes; extended surfaces; CFD simulations; optimization methodology 


\section{Introduction}

A direct implication of the Moore's law, which predicts the increase of density of transistors in dense integrated circuits with time [1], is a growing need for heat dissipation in such circuits due to the increased power density. Typical desktop CPUs (central processing units) can dissipate upwards up to $100 \mathrm{~W}$ and high-end CPUs can approach $280 \mathrm{~W}$ in the stock state. When overclocked, the thermal dissipation requirement can exceed $300 \mathrm{~W}$. Consequently, such CPUs can achieve heat flux values of up to $1 \mathrm{MW} \mathrm{m}^{-2}$, while the heat flux on the hot spots has already reached $10 \mathrm{MW} \mathrm{m}^{-2}$ [2]. Since the conventional heat sinks, usually made of aluminum fins, cannot provide adequate heat dissipation, new cooling methods exploiting forced convection with liquids or phase-change heat transfer need to be utilized $[3,4]$.

Although some methods, such as immersion cooling [5,6] using nucleate boiling [7-10], can provide extremely high cooling performance, their integration into the cooled system is often difficult and expensive, making them less suitable for the consumer market. Heat pipes (HPs), on the other hand, still utilize the intense phase-change heat transfer processes, but in a closed package, making them very convenient for a variety of applications [11]. When one end of a HP is heated, the working fluid vaporizes, and the produced vapor condenses at the other (cold) side; a wick lining of the inside surface is used to return the condensate to the evaporation side. This way, heat is very efficiently transported from one location (for example, the hot surface of a CPU) to another, where it can be dissipated more conveniently as there is more space available (for example, fins and fans can be attached to the cold end of the HPs). Such systems are reasonably cheap, have virtually no operational costs and are easy to implement into electronic systems. Consequently, commercial HP-based CPU coolers are a widely used and mature heat dissipation technology that has existed on the consumer PC market for more than ten years.

To date, a number of studies investigated HP-based CPU cooling. Kim et al. [3] showed that a HP-based CPU cooler is comparable to traditional aluminum-based heat sinks in terms of cooling performance, however, the HP-equipped cooler exhibited better thermal performance with lower fan speed, which translated into a lower noise level. Chang et al. [12] investigated the thermal performance of a HP-based CPU cooler using a thermal resistance model. They report that evaporation and condensation resistances grow with increasing heating power and decreasing fill ratio. Another study investigated the effect of the number of embedded HPs on the total thermal resistance of a CPU cooler [13]. The authors found that two or four HPs, embedded within the heat sink, contribute $36 \%$ and $48 \%$ of the total dissipated heat, respectively. They concluded that the thermal performance is better in case of four HPs, since the total thermal resistance is $0.24 \mathrm{~K} \mathrm{~W}^{-1}$ compared with $0.27 \mathrm{~K} \mathrm{~W}^{-1}$ for the variant with two embedded HPs. Liang et al. [14] carried out a study in which the thermal performance of a heat sink combined with finned U-shape HPs was investigated. They found that the L-ratio (i.e. the ratio of the evaporator section length to the condenser section length) depends on other geometrical parameters such as HP diameter and fin spacing. Another study regarding the total thermal resistance of a U-shaped HP was performed by Elnaggar et al. [15]; in this study, a decrease in total thermal resistance was observed when either the heating power and/or the air velocity were increased. The lowest obtained value of total thermal resistance was $0.18 \mathrm{~K} \mathrm{~W}^{-1}$. However, the heating power and air velocity in this study are rather unrealistic at $24 \mathrm{~W}$ and 
$3 \mathrm{~m} \mathrm{~s}^{-1}$, respectively. Another study reported that total thermal resistances were in range of $0.11-0.19 \mathrm{~K} \mathrm{~W}^{-1}[16]$.

All the aforementioned studies considered several different factors that affect the CPU cooling device's performance. However, an additional factor - the inclination angle of the HPs - was neglected. The effect of the HP orientation on its performance has been studied by a number of researchers, the majority of which found some correlation between the two factors. However, different characteristics of HPs, i.e. their diameter, wick material and structure, fluid type, fill ratio etc., are very important factors that contribute to the inclination effect. Typically, a $0^{\circ}$ orientation is considered to be horizontal and angles from $0^{\circ}$ to $90^{\circ}$ relate to an inclined orientation with the condensing part above the evaporating part. With respect to the inclination angle, values between $40^{\circ}-60^{\circ}$ were typically found to be optimal regarding the HP performance [17-19], although other researchers report a slightly higher optimal angle with a value of $75^{\circ}[20]$. In case of transient behavior of a HP, it was found that the inclination of $15^{\circ}$ decreases the required input power during the startup [21]. Moreover, conclusions of several studies show that the performance of a HP is hindered by certain combinations of the fluid, wick material and structure, since insufficient capillary wicking action is provided to overcome the gravity forces at certain dimensions [22-24]. Based on these findings, it is generally accepted that HP performance is susceptible to the orientation/inclination. However, the impact of the inclination angle on the performance of a single HP compared to a cooling system based on multiple HPs could yield a completely different results due to different heat resistances of the latter system.

One of the early studies in which the dependence of a HP-based CPU cooling system performance on the inclination angle was conducted by Moon et al. [25]. It has been found that the inclination angle of $5^{\circ}$ (among three different angles from $-5^{\circ}, 0^{\circ}$ to $5^{\circ}$ ) yields a higher rate of heat transfer inside a HP. Ji et al. [26] performed an experiment in which a novel integrated flat HP with copper foam as a porous network wick for high heat flux electronic devices was tested under three different inclination angles $\left(0^{\circ}, 90^{\circ}, 180^{\circ}\right)$. The best inclination angle was found to be $0^{\circ}$ in terms of the lowest temperature at the bottom center of the evaporator. Similar results were observed by Yousefi et al. [24], who used a screen mesh wick HP.

In PC CPU cooling applications, the heat pipe serves as a thermal bridge between the base (heat source) and the finned area (heat sink). However, due to a much lower effective thermal resistance of a HP compared to the overall heat transfer coefficient between the fin and the air, special attention should be paid to the design of the finned part of a heat-pipe-based heat sink. In addition to the experiments during which temperature measurements at discrete locations on the fins are performed, a virtual analysis could be conducted by the means of a numerical simulation. A numerical study of three different commercial heat sinks for forced air cooling of PC CPUs was performed by Ozturk et al. [27]. The main output of these simulations were temperature distributions, through which the thermal resistance of all three heat sinks was determined. Elnaggar et al. [15] performed a thermal analysis of a U-shaped multi-heat-pipe PC CPU heat sink using numerical simulations for both natural and forced convection operation. In another study, performed by Choi et al. [16], numerical simulations were used to 
improve the design of a CPU cooler with lower overall thermal resistance. A similar numerical simulation, proposing a novel lightweight heat sink with lower production costs and noise levels, was conducted by Choi et al. [28].

The literature review shows that in the case of a PC CPU cooling system with HPs, there is no established correlation between its performance and the inclination angle, which is also accompanied by a lack of studies in this domain. Hence, a correlation between the inclination angle and the performance of such cooling systems cannot be drawn. To address this issue, this paper presents a study in which the cooling performance of two different commercial HP-based CPU cooling systems is evaluated at inclination angles ranging from $0^{\circ}$ to $180^{\circ}$. In addition to experimental measurements using the manufacturer-supplied stock fan, further measurements were performed with a larger axial blower to reduce the thermal resistance at the air side of the CPU cooler, i.e. on the fins acting as an extended surface. A numerical simulation of the airflow and heat transfer in the channel between two adjacent fins was performed and the simulated fin temperatures were compared to experimentally determined values. Furthermore, the benefits of relatively large but thin fins on commercial CPU coolers are questionable. We therefore establish a methodology for performance optimization through determining the fin effectiveness and fin efficiency based on the results of numerical simulations. Use of the proposed methodology is demonstrated on a commercial HP-based finned CPU cooler. The methodology can be particularly valuable during virtual prototyping and optimization of the fin geometry of finned heat exchangers (HX) by substituting the testing of physical prototypes with a number of simulations. Consequently, the $R \& D$ process could be expedited, while at the same time significant savings of material are possible through the fin geometry optimization. 


\section{Experiments and Methods}

\subsection{Experimental setup}

A custom experimental setup (Fig. 1) was used to evaluate the performance of CPU coolers. The setup consists of a steel base and a steel plate, which is connected to the base via hinges. The setup allows different angles to be set between the base and the plate to which the cooler is mounted. The desired angle is set using one of the angle-setting bars, which were made in specific lengths for discrete angles from $0^{\circ}$ to $180^{\circ}$ in $45^{\circ}$ increments (Fig. 2). Heat generated by the CPU is simulated using four $6 \times 30 \mathrm{~mm} 12 \mathrm{~V}$ cartridge heaters with an individual power of $40 \mathrm{~W}$. The four heaters were inserted into an aluminum block with dimensions of $40 \times 40 \times 10 \mathrm{~mm}^{3}$ designed to replicate the contact surface area of a typical integrated heat spreader (IHS) of a commercial CPU. The maximum theoretical heating power of the setup is therefore $160 \mathrm{~W}$ neglecting heat losses. The setup is designed to withstand temperatures of up to $100{ }^{\circ} \mathrm{C}$, which exceeds allowable temperatures for most CPUs. The heating block is mounted onto the steel plate with four stainless steel screws and steel bushings that provide the desired offset from the base plate. Stainless steel was used due to its low thermal conductivity to reduce conductive heat losses. The heating block is surrounded by a 3-D printed ABS housing, which is filled by pieces of an aerogel blanket with a thermal conductivity of $0.016 \mathrm{~W} \mathrm{~m}^{-1} \mathrm{~K}^{-1}$. The CPU cooler is attached to the experimental setup using manufacturer-supplied hardware and mounting points on aluminum mounting plates with the hole size and pattern being in correspondence with that of the LGA 1150/1151/1155 socket.

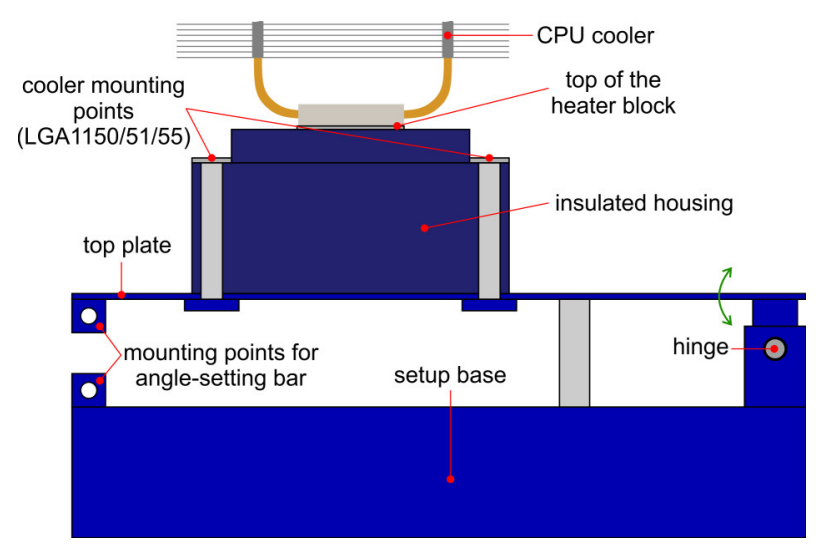

Figure 1. Schematic depiction of the experimental setup; no CPU cooler mounting parts are shown for improved clarity.

The setup is shown in $0^{\circ}$ and $90^{\circ}$ orientation in Fig. 2(c) (lying on its side). The cross-section of the heater block detailing the cartridge heater layout and thermocouple hole positions are shown in Fig. 2(b). The positions of the heaters were chosen to provide uniform heat generation within the block and a near-homogenous temperature field on the contact surface. Measurements using additional thermocouples and IR thermography confirmed that the temperature of the heater block's surface is uniform (with no cooler installed). 

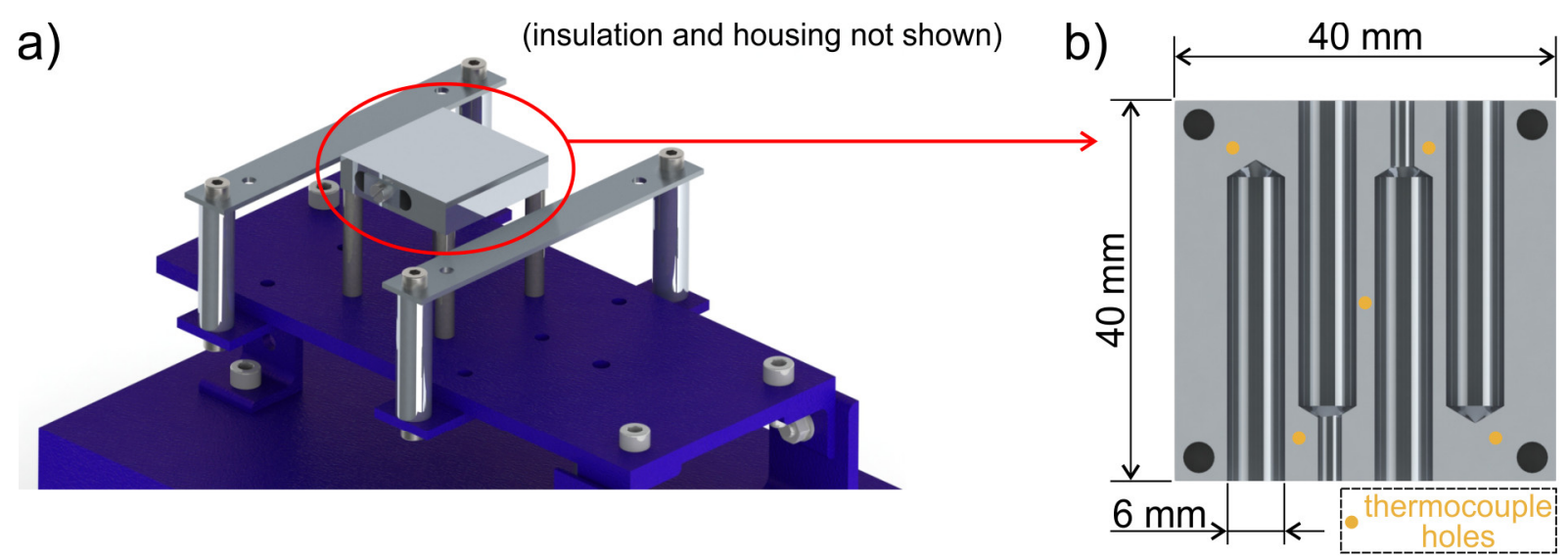

C) $0^{\circ}$ orientation

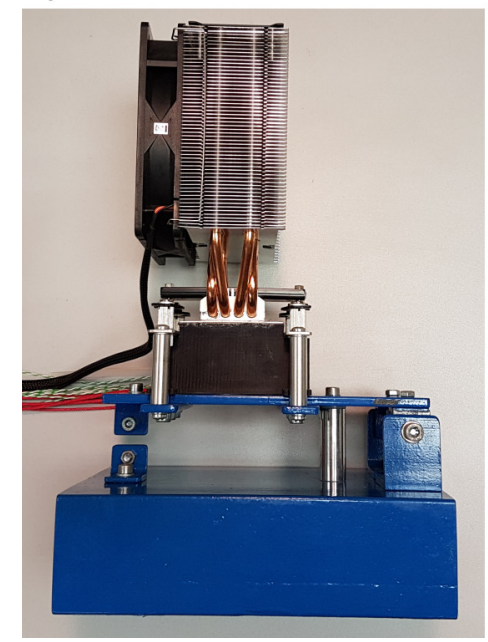

$90^{\circ}$ orientation

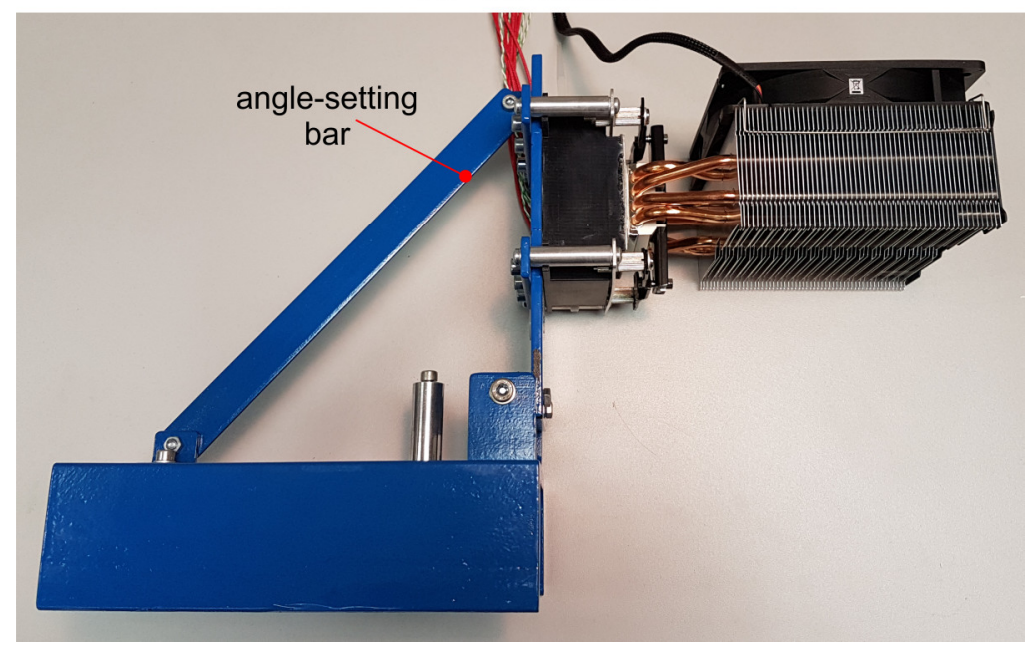

Figure 2. Renders of the 3-D model showing the heater block mounts (a), heater block cross-section (b) and the experimental setup in two possible orientations (c).

Eight K-type thermocouples were used to monitor the temperatures during the experiments. Five thermocouples were integrated into the contact surface of the heater block using Ceramabond $571 \mathrm{~T}$ adhesive to record the temperature of the contact, one was mounted onto the side of the heater block to record its temperature for heat loss calculations and two were used to record ambient temperature in the vicinity of the experimental setup. All thermocouples were calibrated using a thermostatic bath in the temperature range between $10{ }^{\circ} \mathrm{C}$ and $90{ }^{\circ} \mathrm{C}$ in both increasing and decreasing fashion using $10{ }^{\circ} \mathrm{C}$ increments. Heaters were powered using a DC power supply and their power was calculated through the known electrical resistance and supply voltage. A schematic of the data acquisition setup is shown in Fig. 3. Thermocouples were connected to the NI-9212 DAQ module whereas the voltage of the heaters was recorded using the NI-9239 DAQ module. Both modules were integrated into the NI cRIO-9067 chassis. 


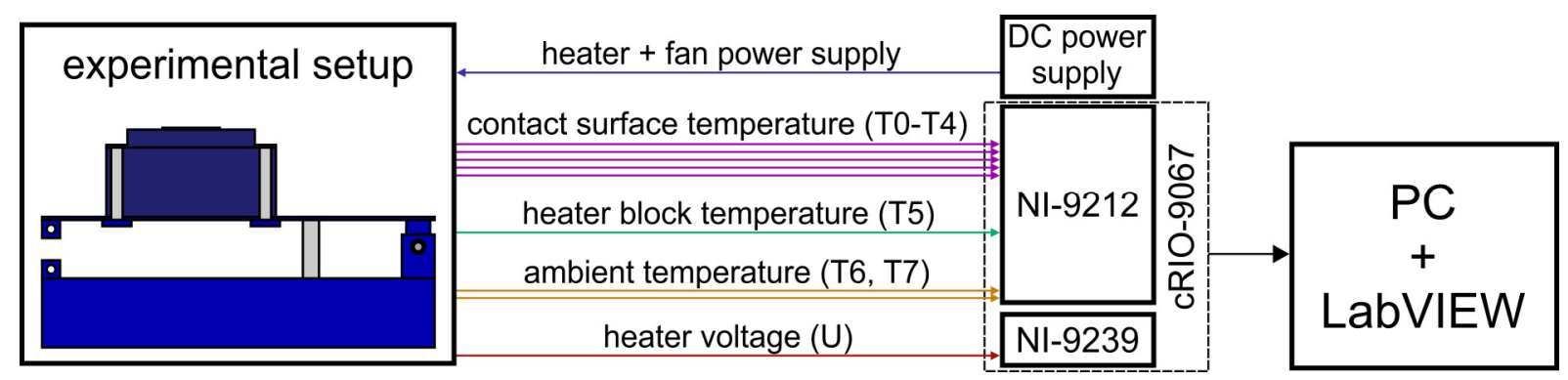

Figure 3. Data acquisition setup.

Heat losses of the heating block and CPU cooler contact were evaluated through a separate preliminary experiment without a CPU cooler on the heater block; the latter was exposed to the surrounding air in the horizontal position and subjected to heat losses through natural convection, radiation and conduction into other parts of the setup. When a cooler is installed, only the conductive term is present as the surface is completely covered by the cooler. Therefore, we determined the correlation between the conductive losses and the heating block temperature. Surface, heating block and ambient temperatures were recorded for a multitude of low heating powers (between 0 and $7 \mathrm{~W}$ ) in a steady state (after approx. $10 \mathrm{~min}$, when the temperature variations were below $0.3 \mathrm{~K}$ in a $5 \mathrm{~min}$ period) and heat losses through natural convection and radiation were calculated. We assumed that the total electrical power input $\dot{Q}_{\text {in }}$ minus the convective and radiative heat losses $\left(\dot{Q}_{\text {conv }}\right.$ and $\dot{Q}_{\text {rad }}$, respectively, evaluated using natural convection and radiation equations suggested in VDI Heat Atlas [29]) equals the conductive losses $\dot{Q}_{\text {cond }}$ :

$$
\dot{Q}_{\text {in }}-\dot{Q}_{\text {conv }}-\dot{Q}_{\text {rad }}=\dot{Q}_{\text {cond }}
$$

The latter term depends solely on the heater block temperature or more precisely on the temperature difference between the heating block and the ambient air (i.e., heating block superheat). A linear function was used to describe the correlation between the aforementioned heating block and the conductive heat losses.

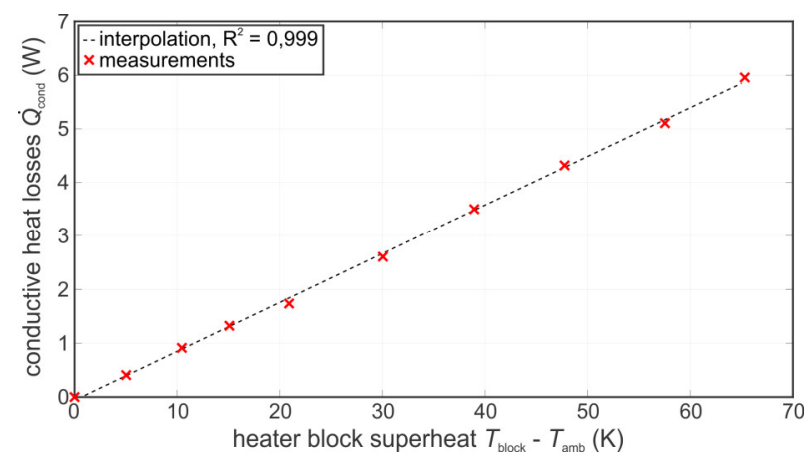

Figure 4. Experimentally obtained correlation between the heating block superheat, defined as $T_{\text {block }}-T_{\text {amb }}$, and conductive heat losses of the experimental setup. 
Heat flux was calculated based on the measured heating power (with losses deducted) by dividing the heating power value with the area of the simulated CPU $\left(16 \mathrm{~cm}^{-2}\right)$. Thermal resistance was calculated as the ratio between heater block's surface superheat (versus the ambient) and the heating power; the value is expressed in $\mathrm{K} \mathrm{W}^{-1}$. Thermal resistance versus heating block's surface heat flux was used to describe the cooling characteristics of the cooling system (i.e., the HP-based finned cooler).

Measurement uncertainty of the temperature measurements was estimated to be below $0.5 \mathrm{~K}$ based on the calibration process for thermocouples, temperature range of the application, and inherent properties of the data acquisition module. Measurement uncertainty of heating power measurement was calculated based on the accuracy and uncertainty of the data regarding the electrical resistance of the heaters and the accuracy of voltage measurement using the NI-9205 module. Calculated relative uncertainty of heater power is $2.8 \%$ and does not account for the possible errors in the heat loss evaluation method. Hence, a more realistic estimate of the heating power uncertainty is $4 \%$ of the measured value. The listed values are combined standard uncertainties; the expanded measurement uncertainty $(95.45 \%$ coverage) of temperature measurement is therefore $1.0 \mathrm{~K}$ and the expanded relative measurement uncertainty of heating power measurement including estimated uncertainty of the heat loss evaluation process is $8 \%$. The resulting measurement uncertainty of thermal resistance depends heavily on the combination of recorded temperature and heating power values. The expanded uncertainty ( $95.45 \%$ coverage) of thermal resistance is estimated to be between $0.10 \mathrm{~K} \mathrm{~W}^{-1}$ and $0.16 \mathrm{~K} \mathrm{~W}^{-1}$ at the lowest heating power (approx. $10 \mathrm{~W}$ ) and approximately $0.009-0.011 \mathrm{~K} \mathrm{~W}^{-1}$ at the highest heating power (approx. $150 \mathrm{~W}$ ).

\subsubsection{Tested CPU cooler geometry}

Two commercially available CPU coolers with heat pipes were used in the experiments; they differed primarily in the configuration of the fins. "Cooler 1" [Fig. 5(a)] had a single stack of fins with all heat pipe condenser ends leading into them, whereas the "Cooler 2" [Fig. 5(b)] had two stacks of slightly smaller fins with four condenser ends of heat pipes leading into each stack (as opposed to all eight in "Cooler 1"). Another major difference was the angle of the airflow between the outlet of the fan and the entrance into the inter-fin area; in "Cooler 1" the angle was $0^{\circ}$ (direct entry), whereas in "Cooler 2 " the angle was approximately $30^{\circ}$. Finally, the heat pipes on "Cooler 1" are oriented vertically and that of "Cooler 2" are oriented at an angle (roughly $45^{\circ}$ ) in the $0^{\circ}$ orientation of the cooler. The geometry of both coolers and other properties are listed in Table 1. 
Table 1. CPU cooler geometry and properties.

\begin{tabular}{cccccc}
\hline Label & $\begin{array}{c}\text { Number of } \\
\text { heat pipes }\end{array}$ & $\begin{array}{c}\text { Heat pipe external } \\
\text { diameter }\end{array}$ & Style & $\begin{array}{c}\text { Number of } \\
\text { fins }\end{array}$ & $\begin{array}{c}\text { Fan airflow } \\
\text { (manufacturer } \\
\text { data) }\end{array}$ \\
\hline Cooler $\mathbf{1}$ & 4 (U-shaped) & $6 \mathrm{~mm}$ & $\begin{array}{c}\text { Single vertical } \\
\text { stack of fins }\end{array}$ & 56 & $134 \mathrm{~m}^{3} \mathrm{~h}^{-1}$ \\
\hline Cooler $\mathbf{2}$ & 4 (U-shaped) & $2 \times 6 \mathrm{~mm}+2 \times 8 \mathrm{~mm}$ & $\begin{array}{c}\text { Two stacks of fins } \\
\text { at an angle }\end{array}$ & 35 per stack & $165 \mathrm{~m}^{3} \mathrm{~h}^{-1}$ \\
\hline
\end{tabular}

a)

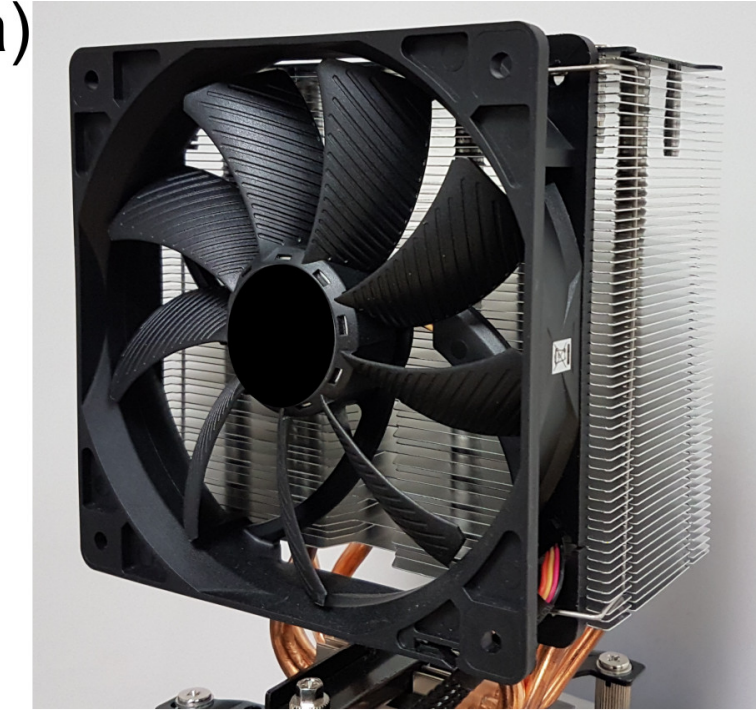

b)

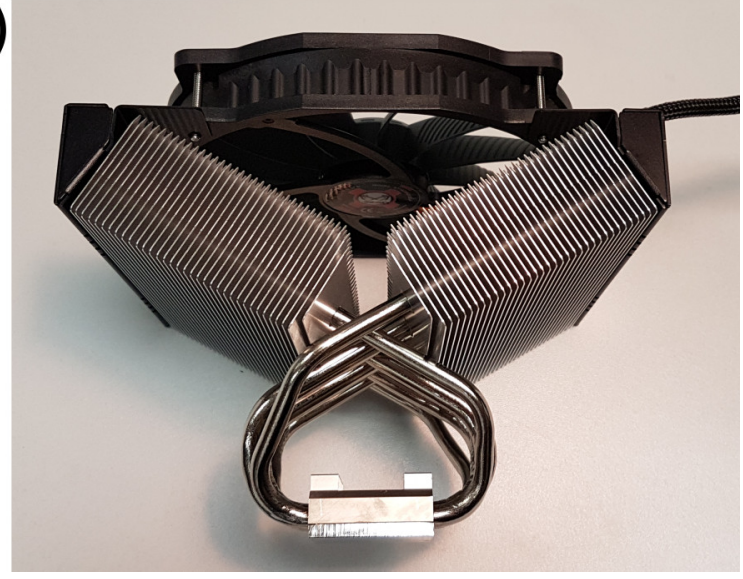

Figure 5. "Cooler 1" (a) and "Cooler 2" (b). 


\subsubsection{Experimental procedures}

The cooling characteristics of each CPU cooler were measured with the cooler at three discrete angles. Before a cooler was mounted onto the setup, both surfaces that would form the thermal contact were cleaned using isopropyl alcohol to remove any residues or grease. A thin layer of a thermal compound (Arctic Cooling Céramique 2) was applied evenly to the surface of the heater block and that of the CPU cooler. Afterwards, the heaters were powered on at approx. $100 \mathrm{~W}$ for several hours in order to stabilize the thermal contact and the thermal compound as per instructions of the manufacturer; cycles of intermittent operation were also simulated by repeatedly turning the heaters off for a short period. During these procedures, the fan on the cooler was run at $100 \%$.

The angle of the heating block (and consequently the orientation of each cooler) was set using the angle-setting bar with an estimated error below $2^{\circ}$. Horizontal orientation with the cooler facing up was termed " $0{ }^{\circ}$ orientation" (Fig. 2), vertical orientation of the heating block as the " $90^{\circ}$ orientation" and inverted horizontal orientation with the cooler facing down as the " $180^{\circ}$ orientation".

For every orientation of each CPU cooler, a set of measurements was performed by increasing the heating power of the heaters in $10 \mathrm{~W}$ increments up to $150 \mathrm{~W}$ or until the surface temperatures reached close to $90^{\circ} \mathrm{C}$ (deemed as an unacceptable temperature for normal CPU operation). At every heater setting, $15-30$ min were provided for the temperatures to reach a steady state; only then the data was collected. The following parameters were recorded in the steady state: heating power (automatically calculated with losses deducted), contact surface temperatures [in five locations, see Fig. 2(b)], heating block temperature and ambient temperature (measured at two locations approx. $1 \mathrm{~m}$ from the setup and not under the influence of the fan's airflow). The entire process was repeated for every orientation and fan power; depending on the particular experiment, the fan on the cooler was either turned off or ran at full power. Based on the collected data, average contact surface temperature was calculated alongside the surface superheat and average ambient temperature for every data point.

In an additional experiment, a large axial blower with a volumetric flow rate of approx. $550 \mathrm{~m}^{3} \mathrm{~h}^{-1}$ was used as a replacement for the standard fan to increase the heat transfer coefficient around the cooler fins. During this experiment, the stock fan was removed from the cooler and air from the blower was funneled towards the cooler through a $1 \mathrm{~m}$ flexible pipe with a diameter of $140 \mathrm{~mm}$; the direction of the airflow generated by the blower in regards to the cooler fins was the same as with a stock fan. This experiment was carried out in the $0^{\circ}$ and $90^{\circ}$ orientation on "Cooler 1".

To record the temperatures of the heat pipes and fins, which were needed for the validation of the numerical simulations, additional measurements were performed using a separate K-type thermocouple with the "Cooler 1 " in the $0^{\circ}$ orientation. During the experiment, the stock fan was running at full power and measurements were made in a steady state for heating powers of $50 \mathrm{~W}, 100 \mathrm{~W}$ and $150 \mathrm{~W}$. 


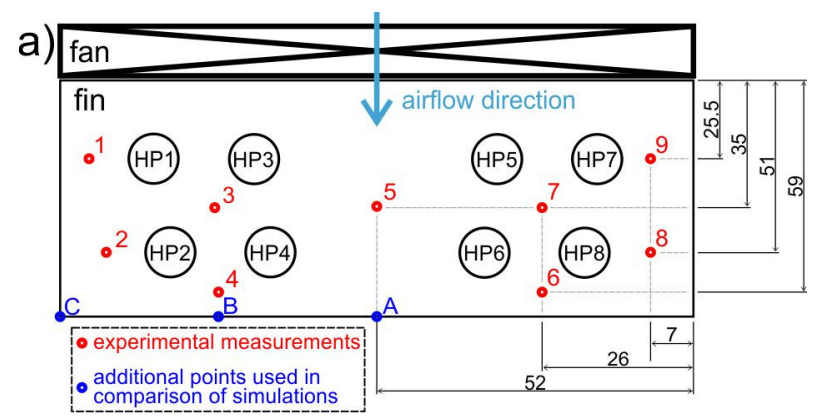

b)

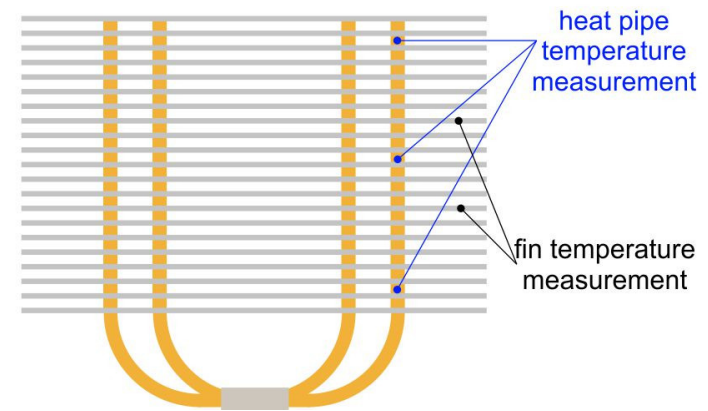

Figure 6. Locations of temperature measurements on cooler's fin (a) and on the cooler's heat pipes (b). Dimensions are in millimeters and the drawing is not to scale. 


\subsection{Numerical simulation of the inter-fin channel airflow and heat transfer}

Based on a retail CPU cooler ("Cooler 1"), a simulation in ANSYS Fluent environment was performed for steady-state operation of the cooler. The main goal of this simulation was to develop a methodology for designing the finned part of the CPU cooling system, which consists of a base, fins and HPs that connect them.

The two parameters that are crucial for developing a CPU cooling system based on fins and HPs with proposed methodology are fin effectiveness and fin efficiency [30]. By calculating these parameters, one can then optimize the geometry of the fins and evaluate how this affects the cooling performance. To calculate these parameters, we determined the temperature distribution on the surface of the fins and heat flow rate through HPs and fins. Considering the complexity of the whole system, simplifications were made in order to minimize the computational requirements.

\subsubsection{Basic assumptions}

For all simulations, the following assumptions were made:

- heat flux from the heat source (CPU) is equally distributed into individual HPs,

- heat losses to the surroundings are neglected,

- airflow generated by the axial fan is equally distributed into all inter-fin channels,

- velocity profile at the inter-fin channel entrance is uniform,

- equal heat flux is transferred to each inter-fin space by the HPs,

- left and right side of the cooler are symmetrical.

Thermal loads of $50 \mathrm{~W}, 100 \mathrm{~W}$ and $150 \mathrm{~W}$, dissipated through the CPU cooler, were considered. Heat flux inside a single HP between a pair of fins was calculated using the following equation:

$$
\dot{q}_{\mathrm{A}}=\frac{\dot{Q}}{N_{\mathrm{HP}}\left(N_{\mathrm{f}}-1\right) A_{\mathrm{HP}}} .
$$

The $N_{\mathrm{HP}}$ denotes the number of heat pipes, $N_{\mathrm{f}}$ the number of fins, $A_{\mathrm{HP}}$ the internal surface area of each HP, $\dot{Q}$ the CPU thermal load and $\dot{q}_{\mathrm{A}}$ the heat flux on the internal surface of the heat pipe.

Inlet velocity at the inter-fin channel entrance was determined from a separate experiment using hotwire anemometry. Cross-sectional area of a pipe mounted onto the axial fan was divided into 6 concentric areas where we measured average velocity in each cross-section. The experiment was repeated 3 times. After measuring the velocities, we calculated each crosssection volumetric flow rate and the full volumetric flow rate of axial fan as the sum of all partial cross-sections. This volumetric flow rate divided by the whole cross section area was the average air velocity, which was used as velocity inlet boundary condition. In the experiment, the stock fan running at full speed was used. The average velocity was $2.49 \mathrm{~m} \mathrm{~s}^{-1}$. 


\subsubsection{Geometry and meshing}

Based on the aforementioned assumptions, the whole system was simplified to include only one channel between two fins with corresponding HP sections. The geometry is shown in Fig. 7.

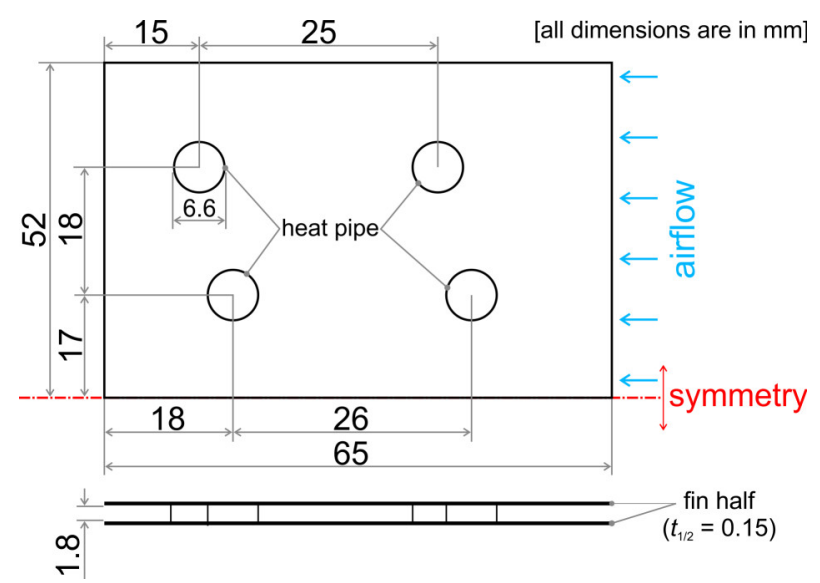

Figure 7. Geometry of the fins and the inter-fin channel of the HP-based CPU cooler used in CFD simulations.

A 3-D model was created and implemented into ANSYS Design Modeler environment. Three meshes were created to conduct the grid independence study using an inflation factor of 1.05. The coarse mesh had approx. 2.16 million cells, the medium density mesh 2.55 million cells and the fine mesh (used in final calculations) 2.97 million cells. The mesh was built with smaller cells near the HPs, since the formation of vortices is expected in this region. The tested turbulent models require the value of the $y+$ parameter to be around 1 . The first required cell height was calculated from Prandtl-Schlichting skin-friction, wall shear stress and friction velocity. The first cell height for each mesh was as follows: $54 \mu \mathrm{m}$ for the coarse mesh, $51.4 \mu \mathrm{m}$ for the medium density mesh and $49.0 \mu \mathrm{m}$ for the fine mesh, which corresponds to $y+$ values between 0.78 and 0.86 . The solution's independence from the mesh was confirmed by comparing the calculation results on all three meshes for the case of $100 \mathrm{~W}$ and using the k- $\varepsilon$ EWT turbulence model in a similar way as previously demonstrated by Siddique et al. [31,32].

\subsubsection{Initial and boundary conditions}

Velocity inlet: Airflow inlet is positioned on the whole cross-section area entrance of the channel. Uniform inlet of air at $27.7{ }^{\circ} \mathrm{C}$ with a velocity of $2.49 \mathrm{~m} \mathrm{~s}^{-1}$ is assumed. These boundary conditions were used to ensure comparability with experimental results and the validation of the simulation.

Pressure outlet: Far-field outlet and side outlet were set to ambient pressure.

HP heat flux: Previously calculated heat flux is set on the inside area of each HP. 
Symmetry: Half of each fin (by its thickness) was considered, as we assumed the temperature distribution would be the same on each half. We also presumed that the heat flux in the zdirection is equal to zero in the middle of the fin's thickness.

Fig. 8(a) shows a schematic of the CFD simulation boundary conditions and Fig. 8(b) shows the inter-fin space with the symmetry of the fins. Material properties of air, copper and aluminum at room temperature were used.

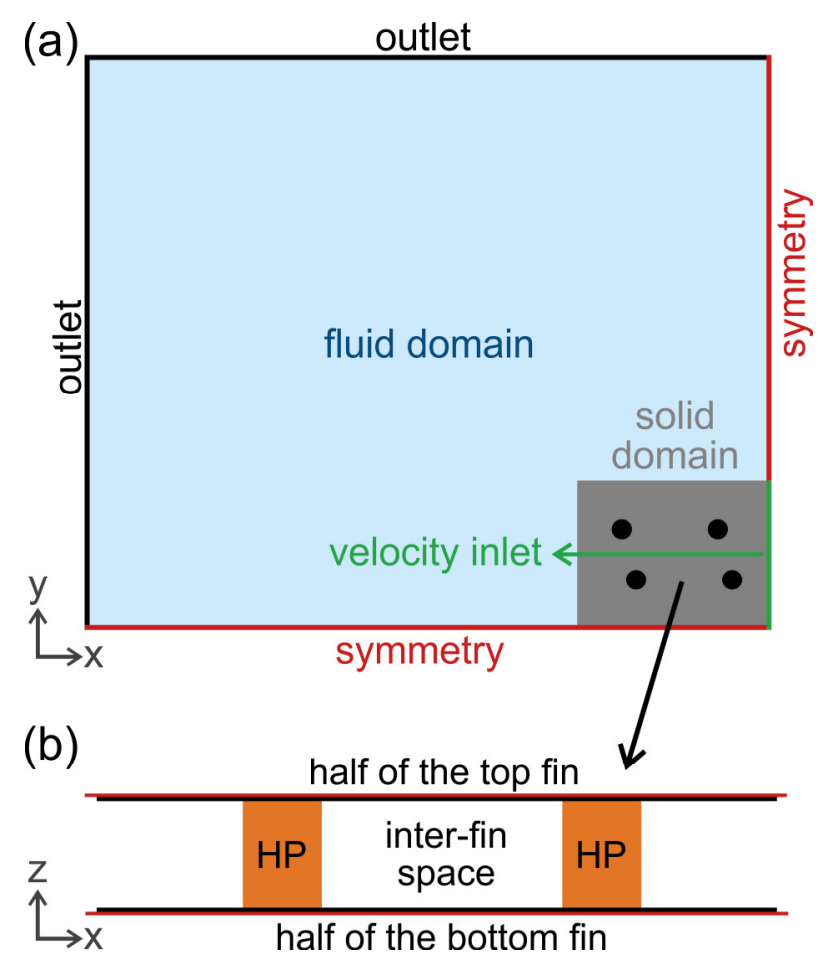

Figure 8. Calculation domain of the CFD simulation and the corresponding boundary conditions (a) and a crosssection of the inter-fin space (b).

\subsubsection{Selection of simulation parameters and models}

In order to choose the appropriate parameters and models for the simulation, the behavior of the flow (turbulent/laminar) needs to be determined. To do so, the Reynolds number for airflow in channel between the fins and also for the second model including only HPs in free flow was calculated.

The Reynolds number of the airflow in the inter-fin channel without accounting for the heat pipes (hydraulic diameter of $3.6 \mathrm{~mm}$ ) is $\mathrm{Re}=557$. However, the Reynolds number of the flow around the cylindrical heat pipes is $\operatorname{Re}=1021$, which implies the formulation of eddies on the lee side of heat pipes. Since a fully turbulent vortex street is expected in flows around cylinders above $\operatorname{Re}=300$ [33], a turbulent model was used to account for the turbulent phenomena in the flow around heat pipes. The k- $\varepsilon$ EWT model was compared against k- $\omega$ SST and k- $\omega$ standard 
models (similar as in the work by Fasquelle et al. [34]) using a coarse mesh for faster calculations. All three tested models gave nearly identical results, which were also validated using experimental data. Final calculations on a fine mesh were conducted using the k- $\varepsilon$ EWT model. Solution method was SIMPLE with second order pressure, second order upwind momentum, second order upwind energy schemes, least square cell-based gradient and first order upwind turbulent kinetic energy scheme. In addition to tracking the residuals of standard CFD equations, the convergence of the heat flux through the fins was also monitored.

\subsubsection{Simulation-based calculations of fin effectiveness and fin efficiency}

The proposed numerical simulations allow us to assess the performance of the fins by performing a fin effectiveness and fin efficiency calculations [30] for different heating powers. The methodology, based on the proposed variables, requires extracting the values of heat transfer coefficients and temperatures that were calculated during simulations from the solid and fluid domains.

\section{Fin effectiveness}

Fin effectiveness is defined as the ratio of the finned heat transfer rate to the base heat transfer rate [35]. To determine this, a simulation of flow between the fins and flow around HPs without fins was performed. When designing a HX using extended surfaces, the fin effectiveness should be at least 2, otherwise the use of fins is redundant. The fin effectiveness was calculated using the following equation:

$$
\varepsilon_{\mathrm{f}}=\frac{\dot{Q}_{\mathrm{fin}}}{\dot{Q}_{\mathrm{base}}}=\frac{\bar{h}_{\mathrm{f}} \cdot A_{\mathrm{f}} \cdot \theta_{\mathrm{f}}}{\bar{h}_{\mathrm{b}} \cdot A_{\mathrm{b}} \cdot \theta_{\mathrm{b}}},
$$

where $\dot{Q}_{\text {fin }}$ represents finned heat transfer rate, $\dot{Q}_{\text {base }}$ represents heat transfer rate of the base, $\bar{h}_{\mathrm{f}}$ and $\bar{h}_{\mathrm{b}}$ represent the area-weighted average heat transfer coefficient between the air and the fin and between the air and the base, respectively. $A_{\mathrm{f}}$ and $A_{\mathrm{b}}$ represent the fin and base surface area, respectively, while $\theta_{\mathrm{f}}$ and $\theta_{\mathrm{b}}$ represent temperature differences between the fin and air and base and air, respectively. Both variables (temperature differences) were calculated using the following equations: $\theta_{\mathrm{f}}=\bar{T}_{\mathrm{f}}-\bar{T}_{0}$ and $\theta_{\mathrm{b}}=\bar{T}_{\mathrm{b}}-\bar{T}_{0}$, where $\bar{T}_{\mathrm{f}}, \bar{T}_{\mathrm{b}}$ and $\bar{T}_{0}$ represent the area weighted average fin, air and HP base temperatures, respectively.

\section{Fin efficiency}

The fin efficiency of the fin is defined similarly to the fin effectiveness; however, the finned heat transfer rate is divided by the maximum possible finned heat transfer rate [35]. This is a theoretical value that can be reached in the limiting case when the fin conduction thermal resistance approaches $0 \mathrm{~K} \mathrm{~W}^{-1}$. This yields the fin efficiency approaching unity. Based on the results of numerical simulations, the fin efficiency was calculated using the following equation: 


$$
\eta_{\mathrm{f}}=\frac{\dot{Q}_{\mathrm{fin}}}{\dot{Q}_{\mathrm{fin}, \max }}=\frac{\bar{h}_{\mathrm{f}} \cdot A_{\mathrm{f}} \cdot \theta_{\mathrm{f}}}{\bar{h}_{\mathrm{f}} \cdot A_{\mathrm{f}} \cdot \theta_{\mathrm{b}}}=\frac{\theta_{\mathrm{f}}}{\theta_{\mathrm{b}}}=\frac{\bar{T}_{\mathrm{f}}-\bar{T}_{0}}{\bar{T}_{\mathrm{b}}-\bar{T}_{0}},
$$

where $\dot{Q}_{\text {fin,max }}$ represents the maximum finned heat transfer rate if the whole surface area of the fin would be at the temperature of the fin base. 


\section{Results and Discussion}

\subsection{Experimental evaluation of cooler performance}

\subsubsection{Passive operation}

Passive operation of "Cooler 1" was tested in multiple orientations with the fan not running or removed altogether. In the $0^{\circ}$ and $180^{\circ}$ orientation the fins are horizontal, which reduces the intensity of natural convection and therefore also the intensity of heat transfer from the cooler to the ambient air. In the $90^{\circ}$ orientation, the fins are vertical, which allows the air to move in the vertical direction between them due to density changes caused by heat transfer from the fins, thus increasing the intensity of the natural convection. As the fan is in the way of air moving between the fins by partially blocking the passage of air, three different scenarios were tested to determine whether this effects the heat transfer intensity and cooler's performance. The fan was either removed, mounted below the fins or above them with the cooler in $90^{\circ}$ orientation.

The results of tests without forced convection (i.e., with the cooler in passive operation) are displayed in Fig. 9. It is clearly noticeable that the horizontal orientation of the fins when the cooler is in either $0^{\circ}$ or $180^{\circ}$ orientations is unfavorable as thermal resistances in excess of $1.46 \mathrm{~K} \mathrm{~W}^{-1}$ were recorded. The highest values of the thermal resistance were recorded with the cooler inverted $\left(180^{\circ}\right.$ orientation), which can be attributed to the combination of low heat transfer intensity from horizontally oriented fins and the heat pipes also being inverted with the evaporation taking place almost vertically above the condenser end. Considerably better cooling characteristics were achieved with the cooler in the $90^{\circ}$ orientation; the results for both the scenario with the fan removed and the fan above the fins are nearly identical, whereas slightly higher thermal resistance was measured with the fan below the fins. The latter can be attributed to impeded entry of the ambient air into the inter-fin space where it replaces the warmer rising air of lower density. The results suggest that the fan above the fins does not obstruct the movement of rising air in a way that would cause a significant impact on the cooling performance. 


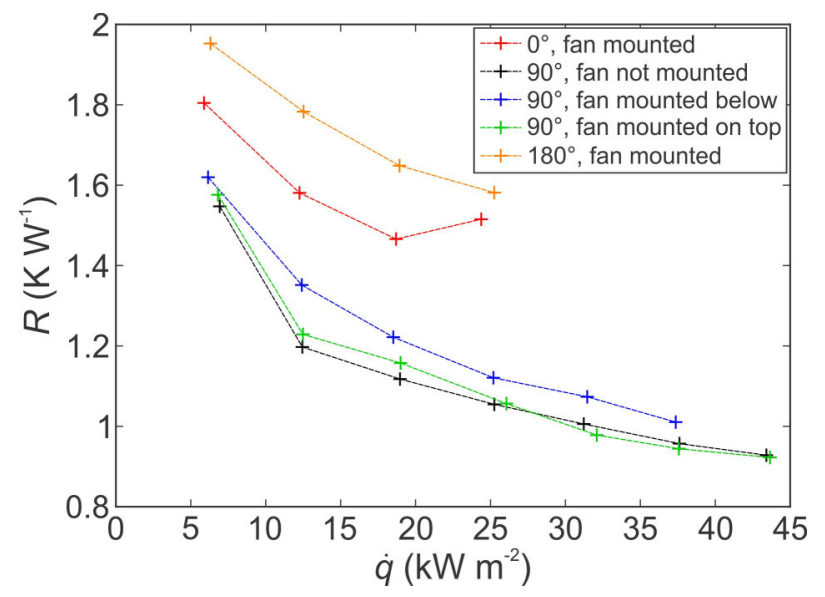

Figure 9. Cooling characteristics of "Cooler 1" in different orientations with the fan not operating.

\subsubsection{Operation with forced convection}

Cooling performance of "Cooler 1" was also tested with the stock fan operating at maximum revolution (i.e. producing maximum airflow). Three distinct orientations were tested and the measurements were repeated twice in each of them. The results are displayed in Fig. 10. It is evident that the differences in cooling performance between various orientations are quite small and no clear trend in terms of the influence of cooler orientation is noticeable. It can be concluded that the major resistance against heat transfer exists on the fins, where the heat is transferred to the ambient air through convection. Compared to the heat transfer in heat pipes, which is based on extremely intensive processes of evaporation (boiling) and condensation, the intensity of forced convection is at least a few orders of magnitude lower. Hence, the reduced performance of heat pipes when outside of optimal orientation does not impact the overall cooling performance of the CPU cooler as it represents only a tiny fraction of the overall thermal resistance between the contact surface and the ambient air $[13,14]$. 


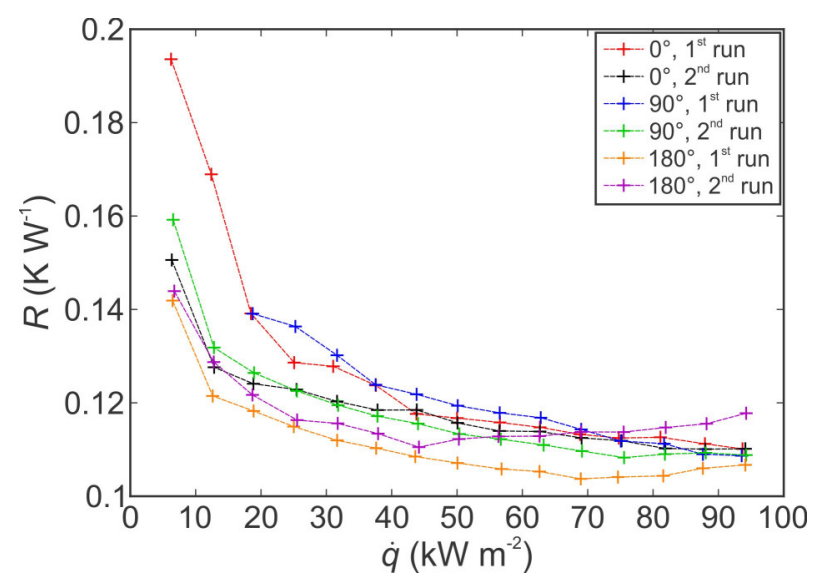

Figure 10. Cooling characteristics of "Cooler 1" in different orientations when operating with the fan at full speed.

Based on the results shown in Fig. 10, we increased the intensity of the forced convection by using a large axial blower instead of the stock fan to produce significantly higher airflow between the fins, thus increasing the velocity of air in the inter-fin region and most importantly promoting higher heat transfer coefficient. Two measurements were performed in the $0^{\circ}$ and $90^{\circ}$ orientation and the results are displayed in Fig. 11. It is evident that the differences between the two orientations are now much more distinct with the cooler performing noticeably better in the $90^{\circ}$ orientation as opposed to the $0^{\circ}$ orientation. This alludes to the fact that HPs offer better performance when in a horizontal orientation, which agrees with the findings of other authors mentioned in the literature review.

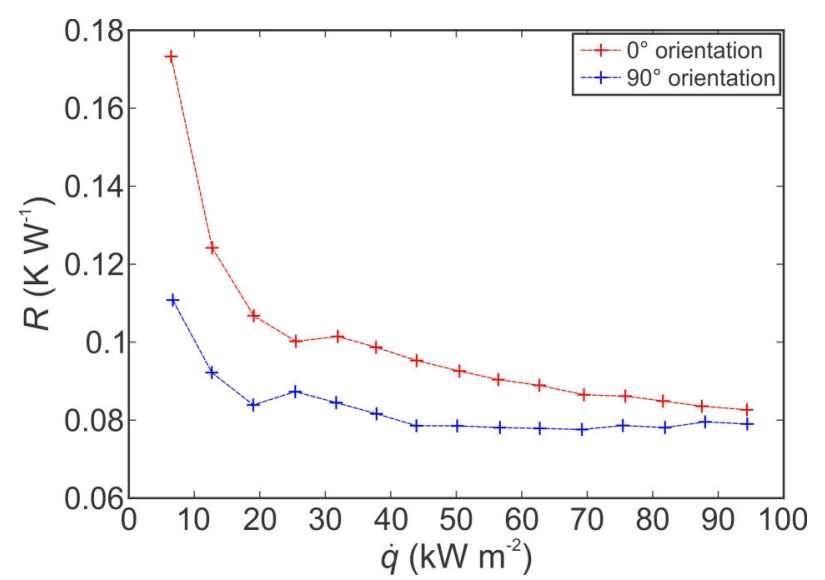

Figure 11. Cooling characteristics of "Cooler 1" in different orientations when operating under the influence of a large external axial blower.

To determine whether the geometry of the cooler has an influence on the cooling characteristics of the cooler in different orientations, measurements were also performed using "Cooler 2". Again, three orientations were tested with the measurements repeated in the $0^{\circ}$ and $90^{\circ}$ 
orientation to achieve higher reliability of experimental results. As the measurements were not repeated in the $180^{\circ}$ orientation, averaged results for $0^{\circ}$ and $90^{\circ}$ orientation are shown in Fig. 12 to avoid confusion. The results suggest that "Cooler 2 " performs similarly in both the $90^{\circ}$ and $180^{\circ}$ orientation and slightly worse in the $0^{\circ}$ orientation. Based on conclusions drawn from the tests performed on "Cooler 1", the best performance in $90^{\circ}$ orientation is sensible. On the other hand, it is somewhat surprising that the $180^{\circ}$ orientation would perform just as well as the $0^{\circ}$ orientation. However, since the heat pipes on "Cooler 2 " are installed at an angle, it is possible that they operate at slightly higher performance when the condenser end is slightly below the evaporator end as it is in the $180^{\circ}$ orientation [1-5] . It is also important to note that the differences are small and measurement uncertainty of the parameters may play a critical role in the correct interpretation of the results.

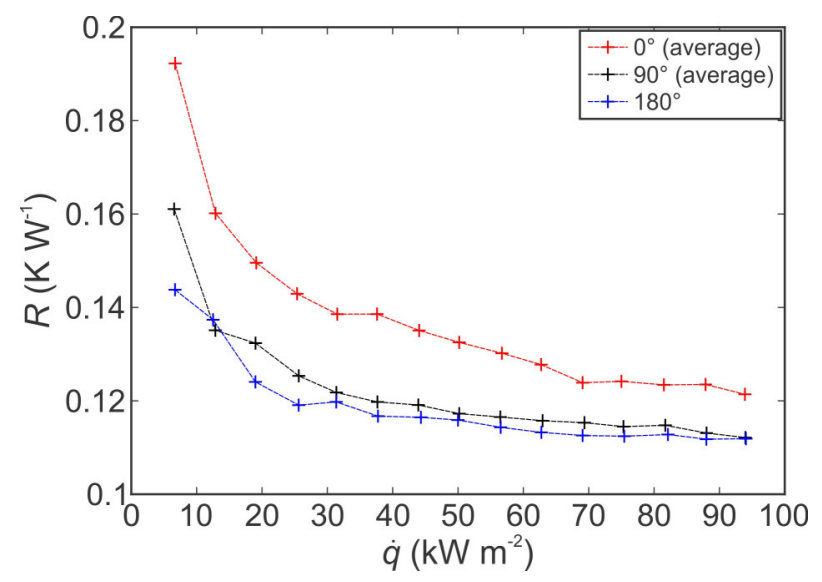

Figure 12. Cooling characteristics of "Cooler 2" in different orientations when operating with the fan at full speed. 


\subsubsection{Comparison of operating modes and cooler types}

A summary of all tests performed on "Cooler 1" is shown in Fig. 13. It is clearly evident that the cooling performance is significantly higher (approx. one order of magnitude) when operating under the influence of forced convection as opposed to passive operation utilizing natural convection. A fourfold increase in the airflow brought on by the use of the axial blower has a limited influence on the improvement of cooling performance of "Cooler 1". Additionally, the aforementioned improvement is much smaller than the improvement obtained by replacing the dependency on natural convection cooling with a forced airflow in the inter-fin area provided by the stock fan.

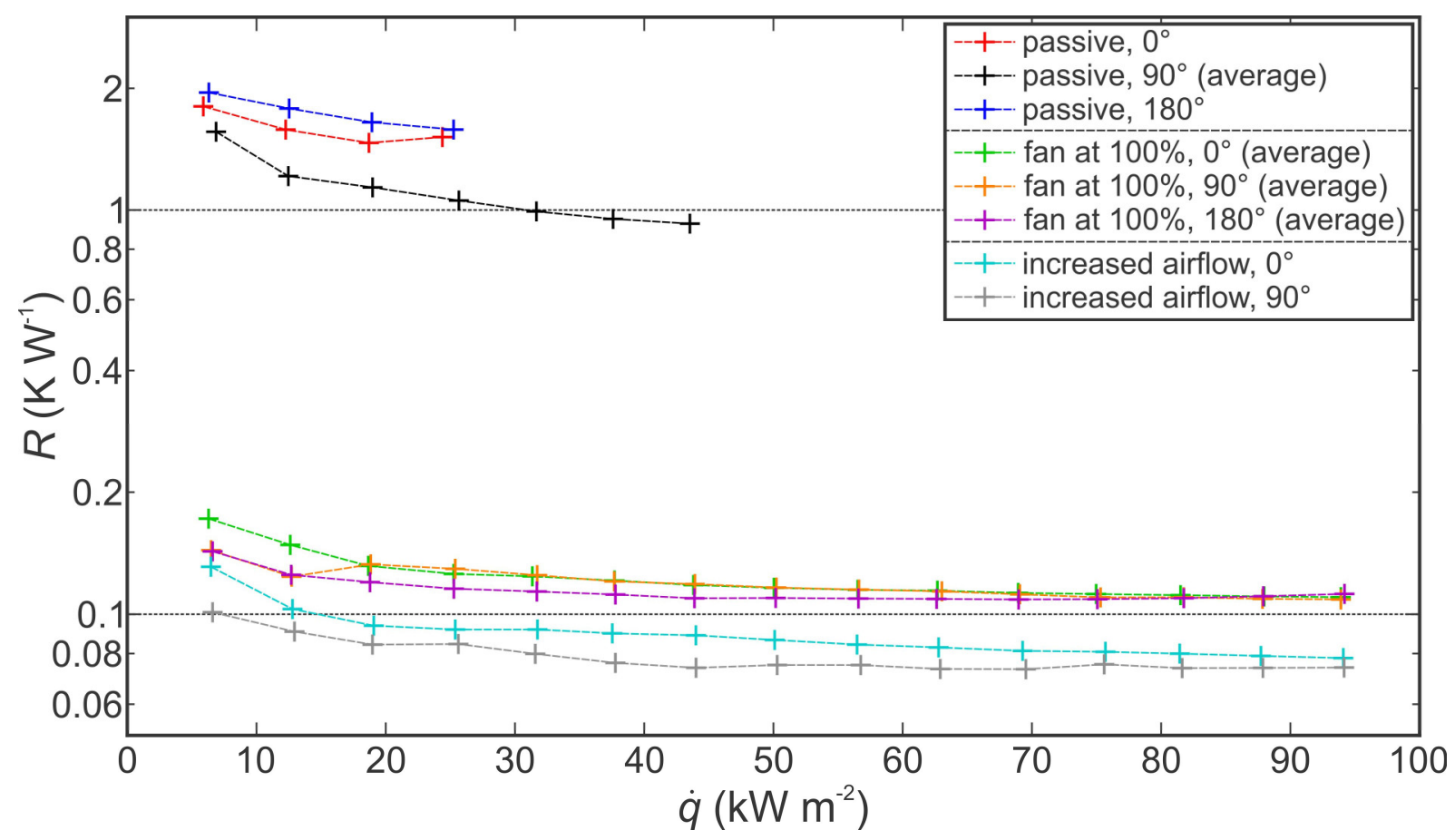

Figure 13. Comparison of the cooling characteristics of "Cooler 1" in different orientations when operating with the fan either turned off or at full speed or under the influence of a large external blower.

A comparison of averaged experimental results obtained with "Cooler 1" and "Cooler 2" operating in different orientations under the forced convection conditions using their respective stock fans (ran at full speed) is displayed in Fig. 14. Similar to trends in Fig. 10, the differences in the cooling performance are small and in the region of the measurement uncertainty. Again, there is no clear superior orientation or cooler geometry. The results allude to the fact that the orientation of a CPU cooler with heat pipes plays a marginal role among the factors influencing the cooling performance. Interestingly, thermal resistance at low heat fluxes was higher in the $0^{\circ}$ orientation on both coolers than in the $180^{\circ}$ orientation. Overall, thermal resistance values of $0.143-0.192 \mathrm{~K} \mathrm{~W}^{-1}$ were recorded at the lowest heat flux, while values between $0.109 \mathrm{~K} \mathrm{~W}^{-1}$ and $0.121 \mathrm{~K} \mathrm{~W}^{-1}$ were obtained at the highest heat flux. This coincides with the typical trend of 
heat pipe performance increasing with increasing heat input (up to a certain point) $[13,14]$. The lowest total thermal resistance of $0.074 \mathrm{~K} \mathrm{~W}^{-1}$ was achieved using an external blower to significantly intensify the forced convection on the finned part of the cooler. (Fig. 11).

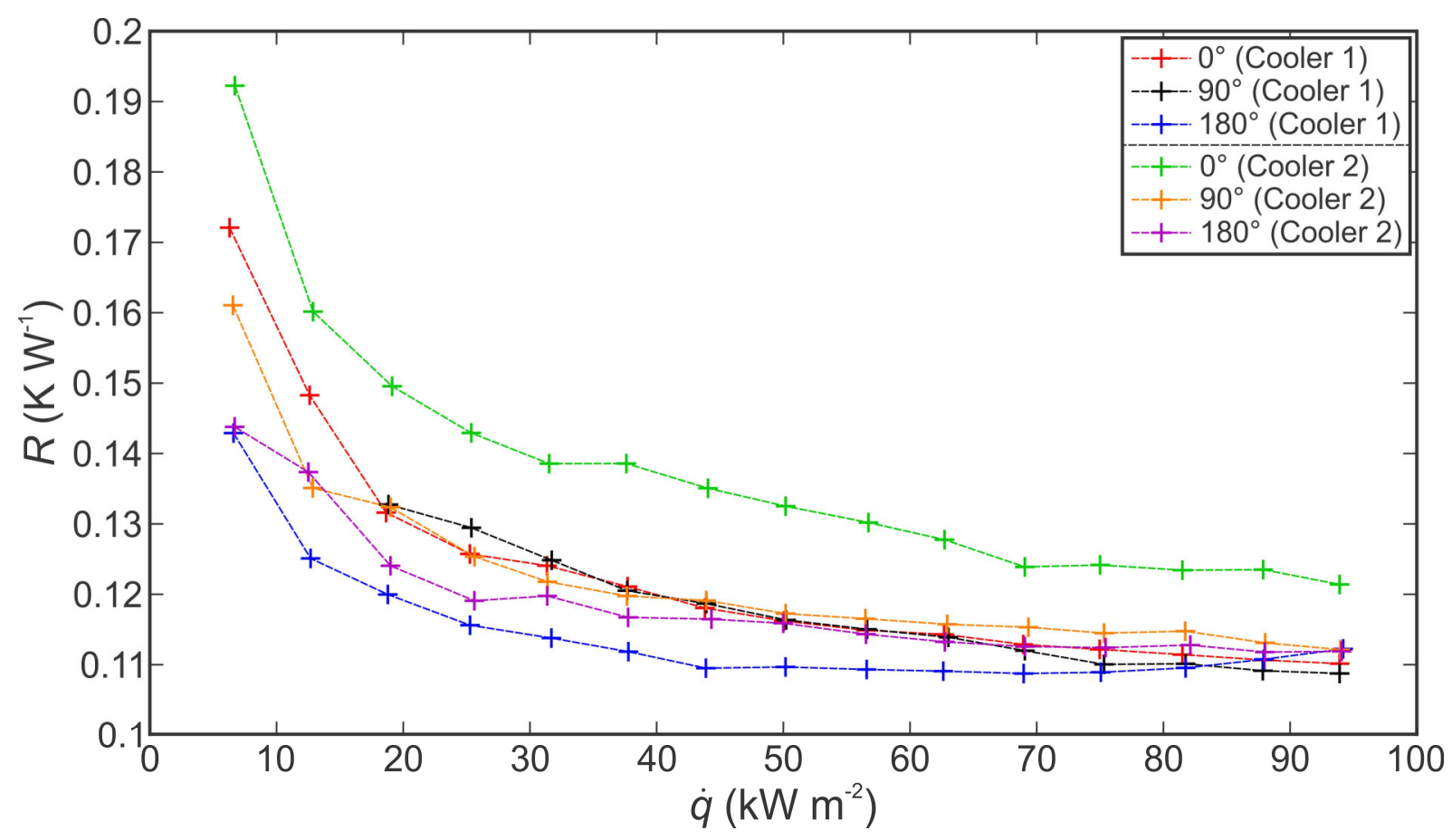

Figure 14. Comparison of the cooling characteristics of "Cooler 1" and "Cooler 2" in different orientations when operating with the fan at full speed. 


\subsubsection{Comparison with values reported by other authors}

A summary of research studies related to the total thermal resistance of a heat sink with HPs is shown in Table 2. In all cases, the minimal thermal resistance achieved in each study is listed (typically recorded at the highest heating power). It can be noted that the total thermal resistances are in the range of $0.1 \mathrm{~K} \mathrm{~W}^{-1}$ to $0.65 \mathrm{~K} \mathrm{~W}^{-1}$, while the present study shows that even lower total thermal resistances can be achieved, especially by increasing the airflow, thereby reducing the convective thermal resistance between the ambient air and the surface of the fin.

Table 2. Comparison of thermal resistance values of finned heat sinks with heat pipes reported by other authors.

\begin{tabular}{|c|c|c|c|c|c|}
\hline Author & $\begin{array}{c}\text { Number } \\
\text { of heat } \\
\text { pipes }\end{array}$ & $\begin{array}{l}\text { Heating power } \\
\text { (W) }\end{array}$ & $\begin{array}{c}\text { Heat pipe } \\
\text { orientation }\end{array}$ & $\begin{array}{l}\text { Heat pipe } \\
\text { shape }\end{array}$ & $\begin{array}{c}\text { Total thermal } \\
\text { resistance }\left(\mathrm{K} \mathrm{W}^{-1}\right)\end{array}$ \\
\hline Kim et al. [3] & 2 & 75 & Horizontal & L-shape & 0.42 \\
\hline Chang et al. [12] & 1 & 140 & Vertical & U-shape & 0.65 \\
\hline Wang et al. [13] & 2 and 4 & $\begin{array}{c}140 \text { (2 HPs) and } \\
140 \text { (4 HPs) }\end{array}$ & Horizontal & L/U-shape & $\begin{array}{l}0.27 \text { (2 HPs) and } \\
0.24 \text { (4 HPs) }\end{array}$ \\
\hline Liang et al. [14] & 1 & 65 & Vertical & U-shape & 0.64 \\
\hline Elnaggar et al. [15] & 3 & 24 & Vertical & U-shape & 0.18 \\
\hline Choi et al. [16] & 2 & 130 & Vertical & $\Omega$-shape & 0.11 \\
\hline Wang et al. [40] & 2 & 140 & Horizontal & U-shape & 0.27 \\
\hline Present study - Cooler 1 & 4 & 150 & Vertical & U-shape & 0.11 \\
\hline $\begin{array}{l}\text { Present study - Cooler } 1 \\
\text { with increased airflow }\end{array}$ & 4 & 150 & Vertical & U-shape & 0.074 \\
\hline
\end{tabular}




\subsection{Numerical simulations}

\subsubsection{Evaluation of the simulation approach}

The validity of the simulations was checked in multiple ways. First, a grid independence study was conducted to confirm that the solution does not depend on the density of the mesh used for simulations. The resulting temperature distributions across the surface of a simulated fin at $100 \mathrm{~W}$ conducted using the k- $\varepsilon$ EWT turbulence model are shown in Fig. 15(a) for the fine mesh (2.97 million cells), Fig. 15(b) for the coarse mesh (2.16 million cells) and Fig. 15(c) for the medium density mesh with 2.55 million cells. It can be observed that the temperature distribution is identical in all three cases.

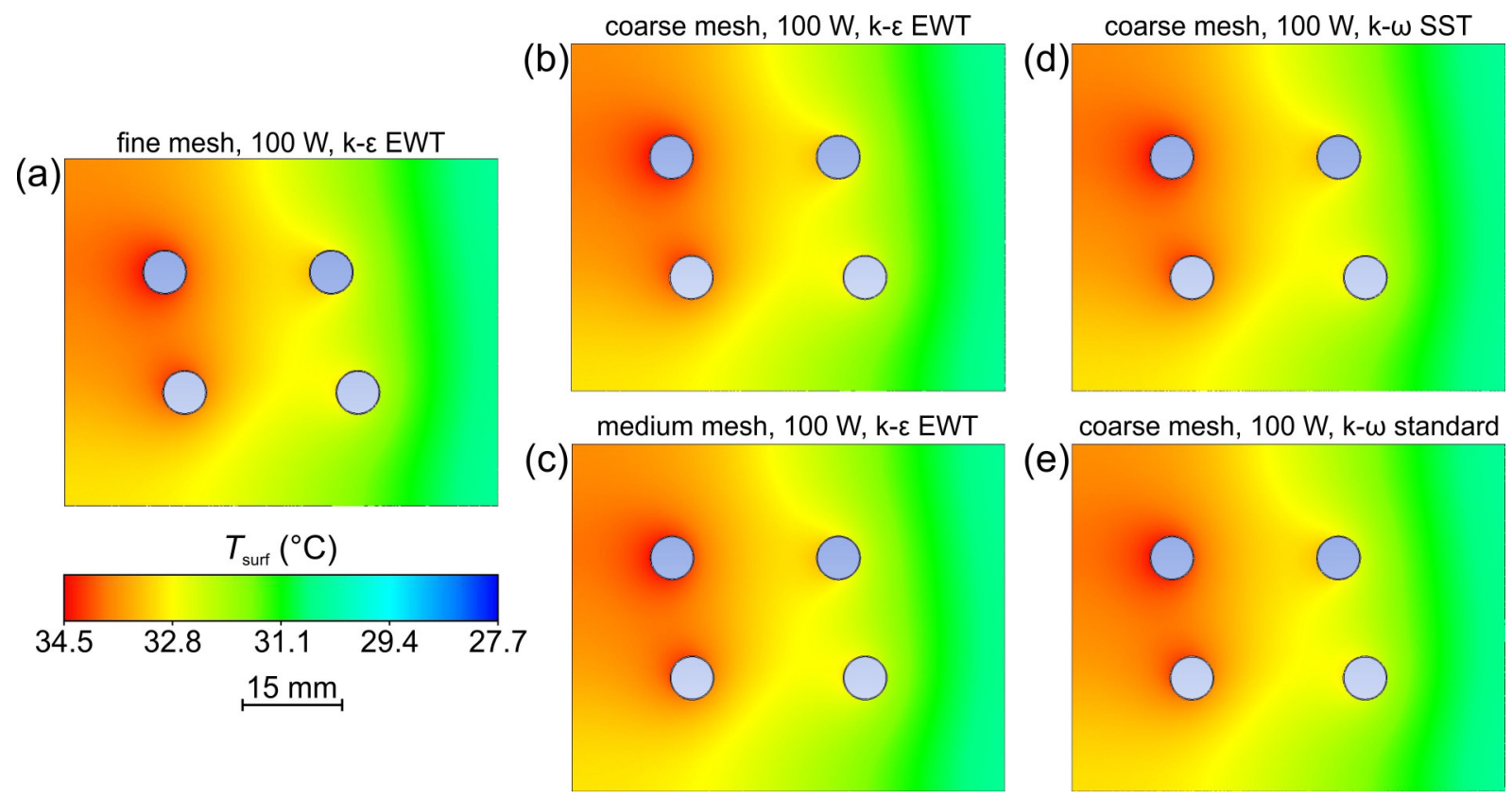

Figure 15. Temperature distribution across a fin at $100 \mathrm{~W}$ using the k- $\varepsilon$ EWT model and either a fine (a), coarse (b) or medium density mesh (c). Temperature distribution across a fin at $100 \mathrm{~W}$ using a coarse mesh and either k- $\omega$ SST (d) or k- $\omega$ standard model (e). The same temperature scale applies to all plots.

The grid independence was further confirmed by comparing the area-averaged temperatures of the top and bottom fins and the volume-averaged temperature of the fluid between the fins as shown in Fig. 16(a). The differences resulting from different mesh density are below $0.05 \mathrm{~K}$. Fig. 16(b) shows the standard deviations of the temperatures shown in Fig. 16(a). The deviations corresponding to different mesh densities differ from one another by less than $0.02 \mathrm{~K}$.

Figure 17(a,b) shows a comparison of temperatures sampled at specific locations as shown in Fig. 6(a). The differences in the temperature in the middle of the fluid domain between different mesh densities range from $0.02 \mathrm{~K}$ to $0.19 \mathrm{~K}$. The differences in the surface temperature (the key parameter in our study) between different mesh densities range from $0.014 \mathrm{~K}$ to $0.10 \mathrm{~K}$. 
The order of grid convergence $p$ was calculated based on surface temperatures sampled at significantly different locations [points \#1, \#4 and B from Fig. 6(a)]. The resulting orders of convergence are 8.25, 10.1 and 28.8 for temperatures at points \#1, \#4 and B, respectively. Since the calculated orders of convergence are positive and the differences in temperatures at selected points between the coarse and medium density mesh are greater than between the medium density and the fine mesh, we can conclude that the solution is grid independent and the fine mesh is dense enough to provide accurate simulation results.
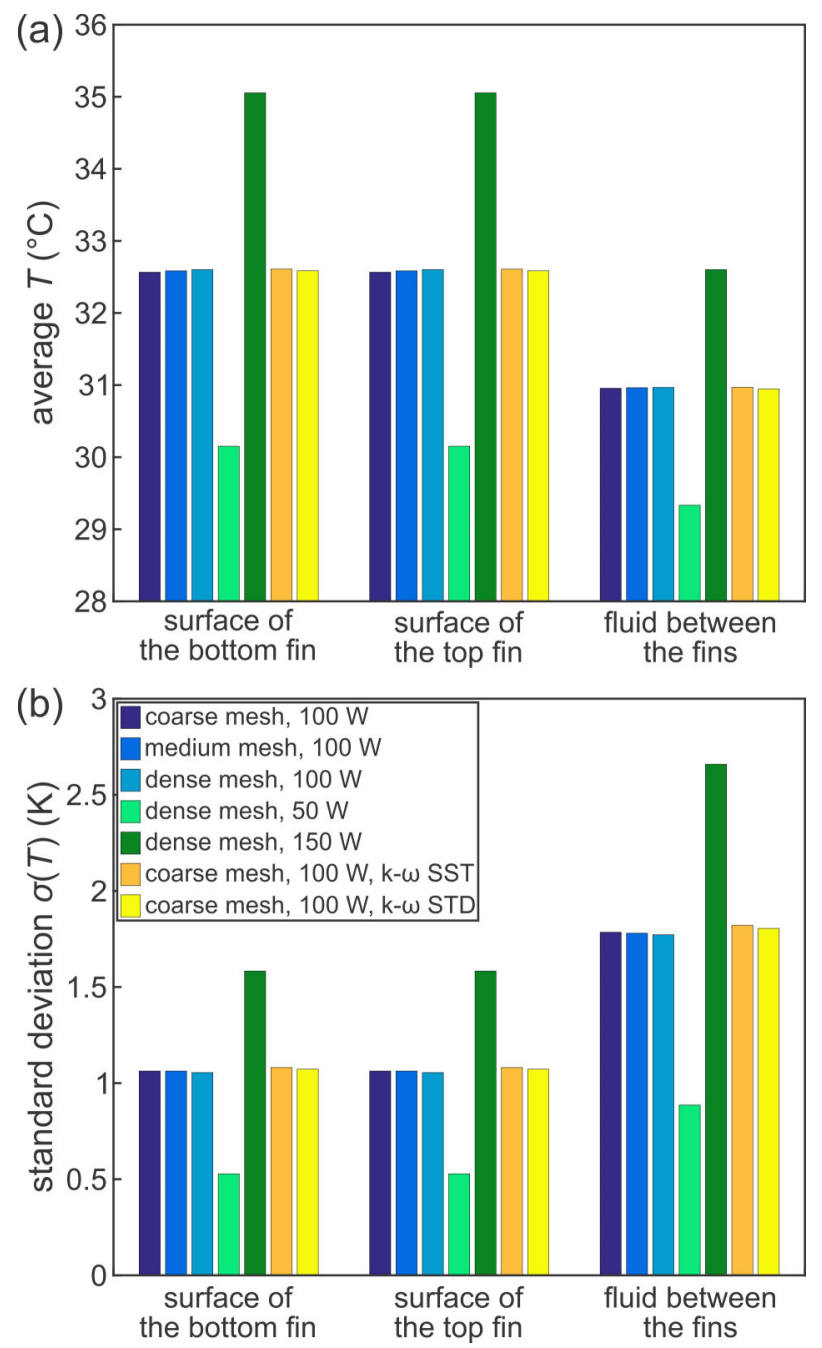

Figure 16. Comparison of surface-averaged temperatures of the bottom and the top fin and the volume-averaged temperature of the fluid between the fins for different mesh densities, heating powers and turbulence models (a) and comparison of standard deviation of these temperatures (b). The same legend applies to both plots.

The analyses shown in Figs. 15-17 were also used to compare different turbulence models and aid in deciding which model to use in final calculations. It is evident that the temperature distribution across a fin at $100 \mathrm{~W}$ on a coarse mesh is identical when using the k- $\varepsilon$ EWT model [Fig. 15(b)], the k- $\omega$ SST model [Fig. 15(d)] or the k- $\omega$ standard model [Fig. 15(e)]. These simulations were also used to obtain data in Fig. 16; the difference in average temperatures is 
below $0.05 \mathrm{~K}$ for all three turbulence models. Similarly, the difference between the standard deviation of these temperatures is below $0.04 \mathrm{~K}$ in all three cases.
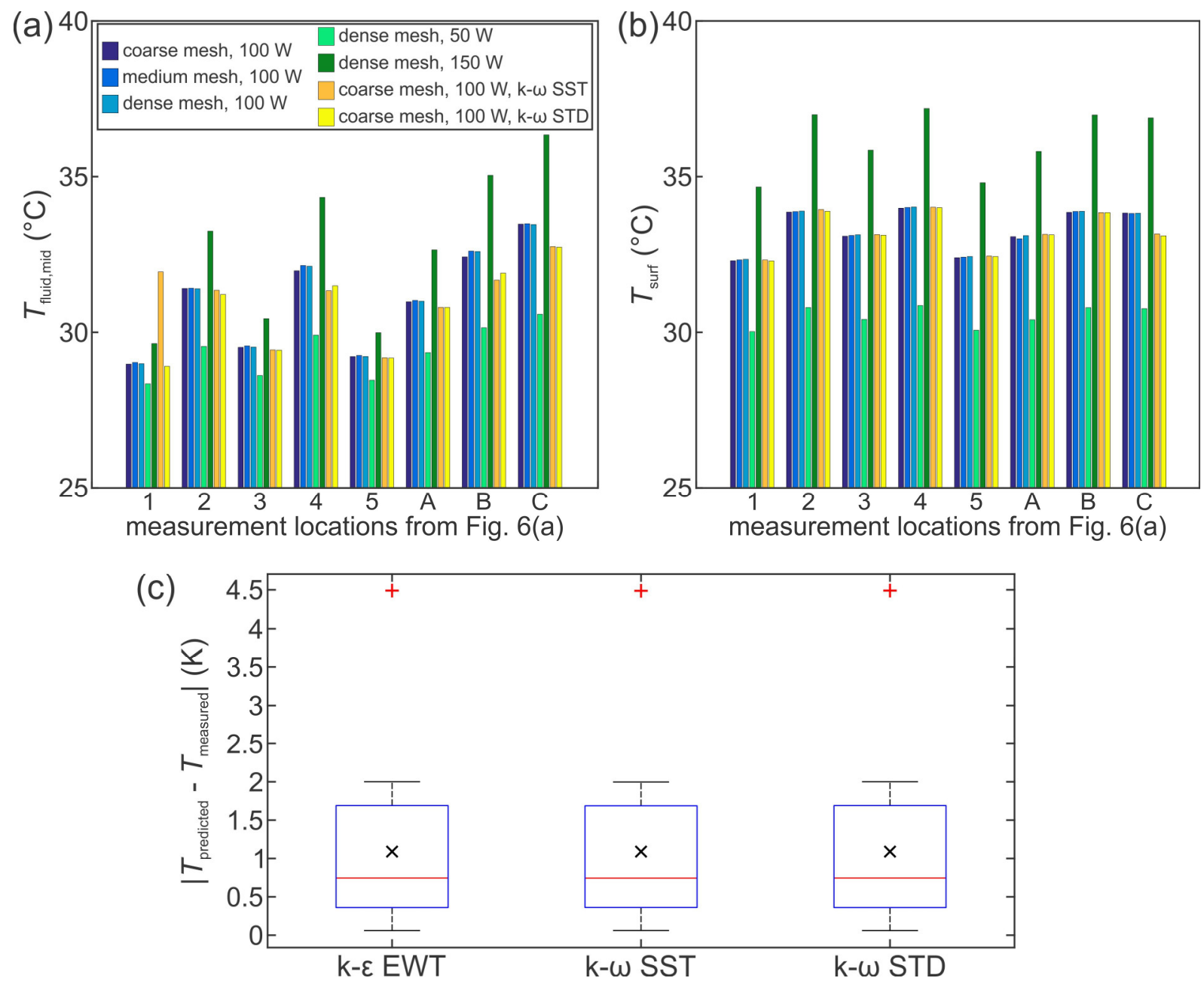

Figure 17. Eight-point comparison of the temperature of the fluid in the middle of the inter-fin channel (a) and the temperature of the fin surface (b); the same legend applies to both plots. Boxplot showing the validation of simulation results against measured temperatures for different turbulence models on a coarse mesh at $100 \mathrm{~W}(\mathrm{c})$.

The three considered turbulence models were also compared based on point-wise sampled temperatures as shown in Fig. 17(a,b). Here, the deviations between the results produced by simulations using different turbulence models are more noticeable when comparing the temperature of the fluid in the middle of the inter-fin channel. However, the only pronounced deviation exists for the point \#1 when using the k- $\omega$ SST model. The deviations between the temperatures in the remaining 7 points are between 0.05 and $0.75 \mathrm{~K}$. As mentioned previously, the temperature of the fin's surface is the key parameter in our study; here, the deviations between results of simulations using different turbulence models are much lower and do not exceed $0.08 \mathrm{~K}$ with an exception of a deviation at point $\mathrm{C}$, where the differences reach $0.73 \mathrm{~K}$. 
Temperatures sampled at points \#1-\#5 were used to compare results of numerical simulations with measured temperatures to evaluate the validity of the simulation. This comparison is shown in the form of boxplots for three different turbulence models in Fig. 17(c). The deviations between the numerical and measurement results are nearly identical for all three turbulence models with a mean deviation of $1.1 \mathrm{~K}$, a median of $0.74 \mathrm{~K}$, one outlier and no detected skewness of the distribution.

Based on the shown analyses we conclude that (i) the numerical model describes the physics of the observed process well and pertinent conclusions can be drawn from the simulations, (ii) the solution is grid independent and (iii) all tested turbulence models will provide extremely similar calculation results. The $\mathrm{k}-\varepsilon$ model used on a fine mesh was chosen for further calculations due to favorable convergence and slightly faster calculations as with the k- $\omega$ models.

\subsubsection{Results of simulations}

The streamlines of the airflow in the inter-fin space of a CPU cooler are shown in Fig. 18(a). Vortices expectedly form behind each heat pipe and the flow can also be seen exiting the interfin space at an angle to the original inlet direction. The temperature distribution of a fin for the case of heating power of $100 \mathrm{~W}$ is shown in Fig. 18(b). The temperature is lowest where the airflow enters the inter-fin space and the highest behind the second column of HPs, which are exposed to air that has already warmed up after flowing around the first two HPs.

(a)

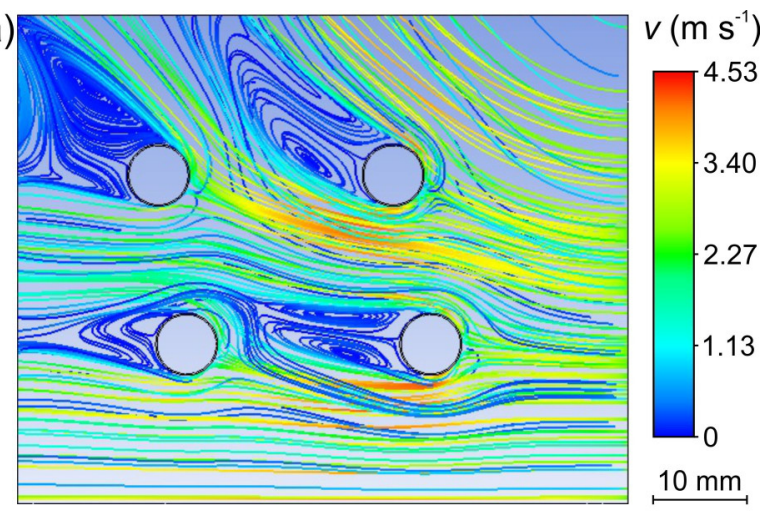

(b)

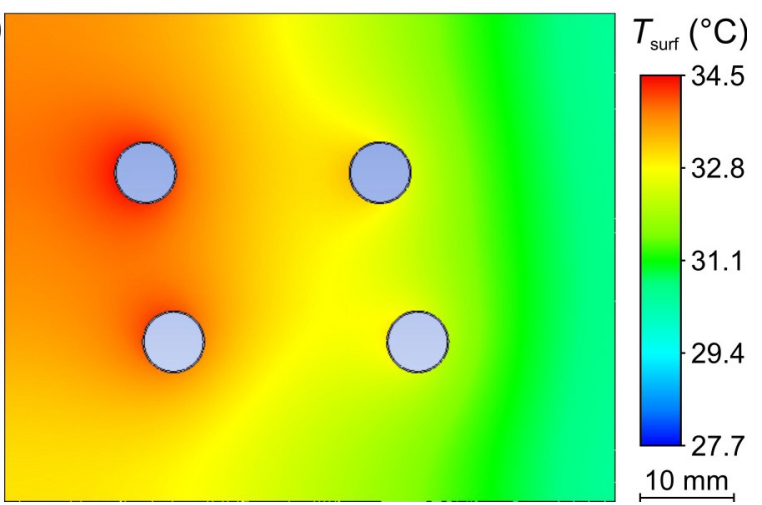

Figure 18. Streamlines of airflow in the inter-fin space (a) and the temperature distribution across the fin at $100 \mathrm{~W}$ (b). 
An experimental validation of the numerical simulations was performed by comparing the predicted (based on numerical simulation) and measured temperatures. Locations of temperature measurements on the fin are shown in Fig. 6(a). A comparison was performed for all three heating powers $(50 \mathrm{~W}, 100 \mathrm{~W}$ and $150 \mathrm{~W})$ for two different fins, as Fig. 6(b) suggests. Altogether, there were 54 temperature measurements, which were used for experimental validation. Six measurement points are missing, which is due to the fact that for each heating power, the location \#5 is inaccessible in the higher parts of the fins due to the fin geometry. A comparison between the predicted and measured temperatures for all three heating powers for all locations is shown in a boxplot in Fig. 19. Considering all the values in Fig. 19, the average difference between the predicted and measured temperature is $1.0 \mathrm{~K}$ (represented by the cross), while the median of all values is $0.94 \mathrm{~K}$. Fifty percent of all values lie between the first $-\mathrm{Q} 1$ $(0.50 \mathrm{~K})$ and the third quartile - Q3 $(1.28 \mathrm{~K}) .24 .1 \%$ of all values lie between the minimum $(0 \mathrm{~K})$ and the Q1; there are two outliers, which represent $3.7 \%$ of all values. To conclude, the experimental validation shows that the numerical simulation has satisfactory agreement with the experiments, while from the statistical point of view, all values are equally distributed (symmetrical) and with little skewness. We estimate that an even better agreement with experimental results could be achieved if the fan-generated flow pattern was considered as the inlet condition, which would, however, results in much more complex simulations.

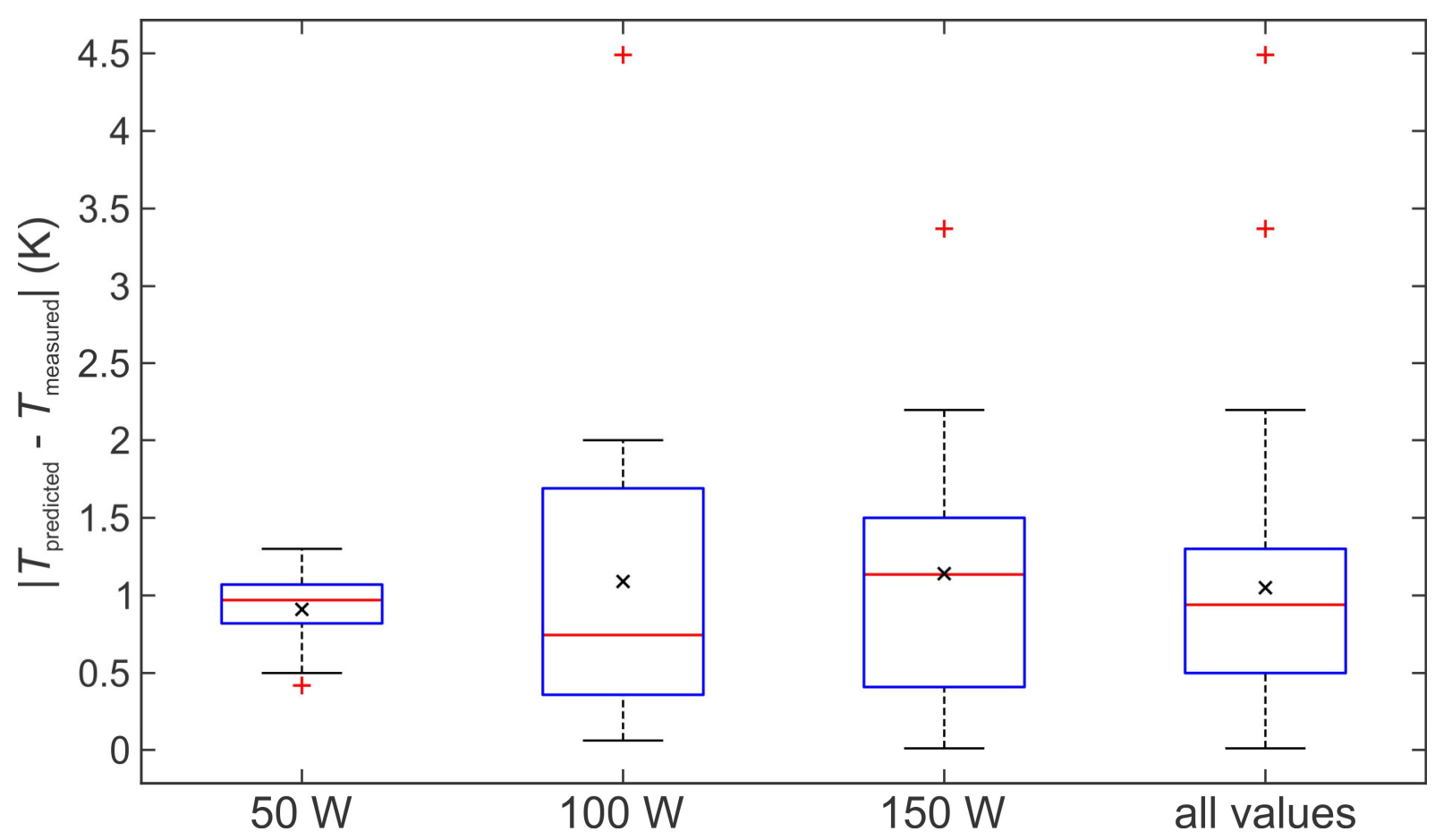

Figure 19. Boxplot comparison of differences between predicted temperatures (from numerical simulation) and measured temperatures. 


\subsubsection{Fin effectiveness and fin efficiency}

\section{Stock fin}

Fig. 20 shows fin effectiveness of a stock fin for all three heating powers, which appears to be invariant in respect to the heating power. The results suggest that the finned heat transfer rate $\left(\dot{Q}_{\text {fin }}\right)$ and heat transfer rate of the base $\left(\dot{Q}_{\text {base }}\right)$ are showing a linear dependence on the heating power. Based on the results regarding the fin effectiveness of the presented geometry of the CPU cooler under consideration, the use of fins is justified, since all three values of fin effectiveness are almost three times higher compared to the widely accepted threshold value of $2[30]$.

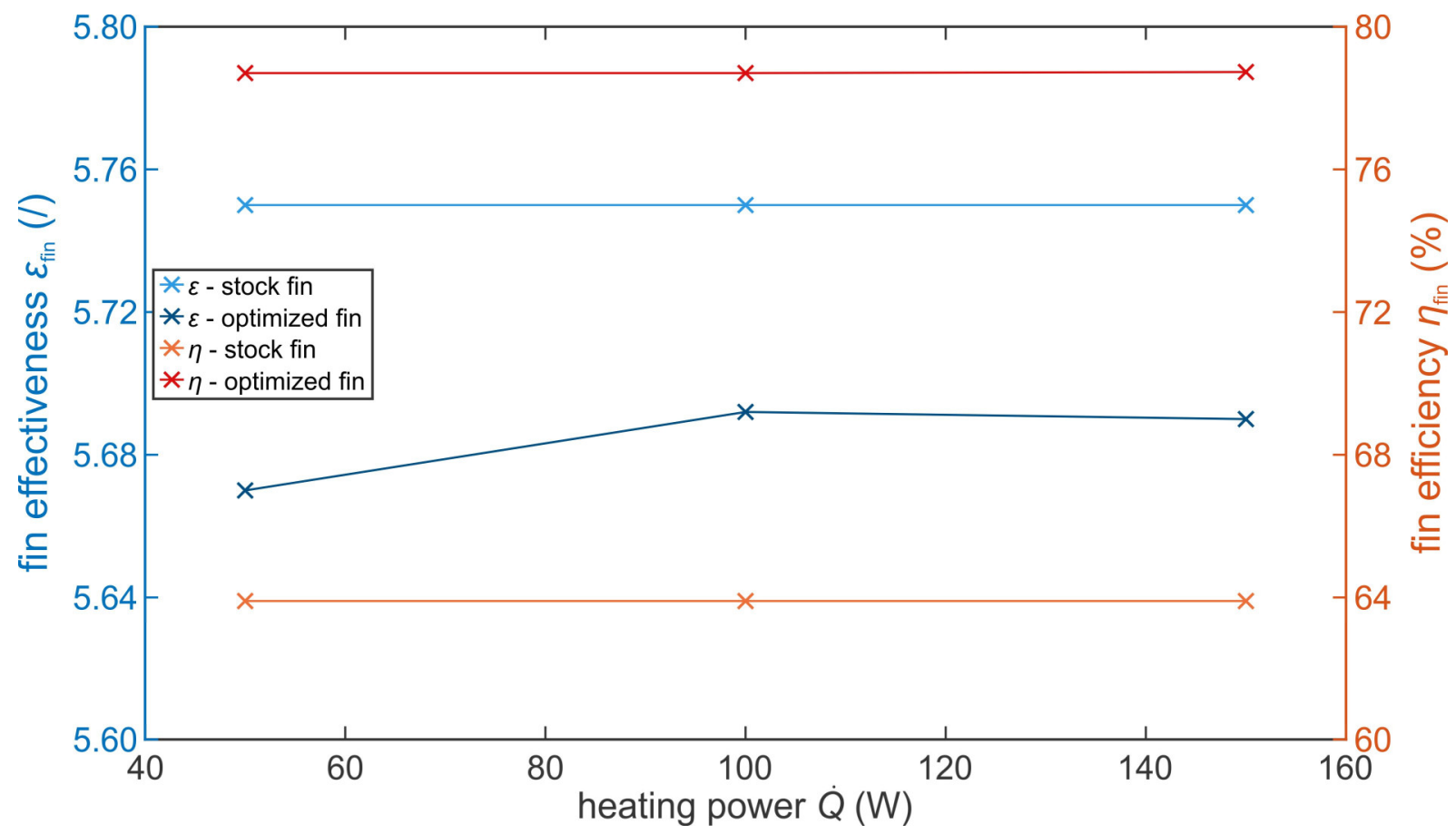

Figure 20. Fin effectiveness and fin efficiency of the stock and optimized fin at different heating powers.

The fin efficiency of the stock fin remains nearly constant regardless of the heating power within the range of our analysis.

\subsubsection{Optimized fin}

The fin efficiency values of a stock fin show that the current placement of HPs is not optimal, as evident from Fig. 18(b), since the temperatures close to the air inlet on a stock fin are much lower compared to the left part (at the air outlet). Considering that in this configuration the HPs reject heat to the ambient mainly through fins, some geometric changes could bring the fin efficiency closer to $100 \%$. This in turn represents possible savings with regards to fin's weight and cost of material. Hence, another set of simulations was performed using a reduced size of 
the fin ("optimized fin"). All the initial and boundary condition were left unchanged. The stock fin was cut $15 \mathrm{~mm}$ from the right edge, as indicated in Fig. 21. The temperature distribution on an optimized fin is shown in Fig. 22(a) together with the temperature distribution on a stock fin [Fig. 22(b)] for the heating power of $100 \mathrm{~W}$.

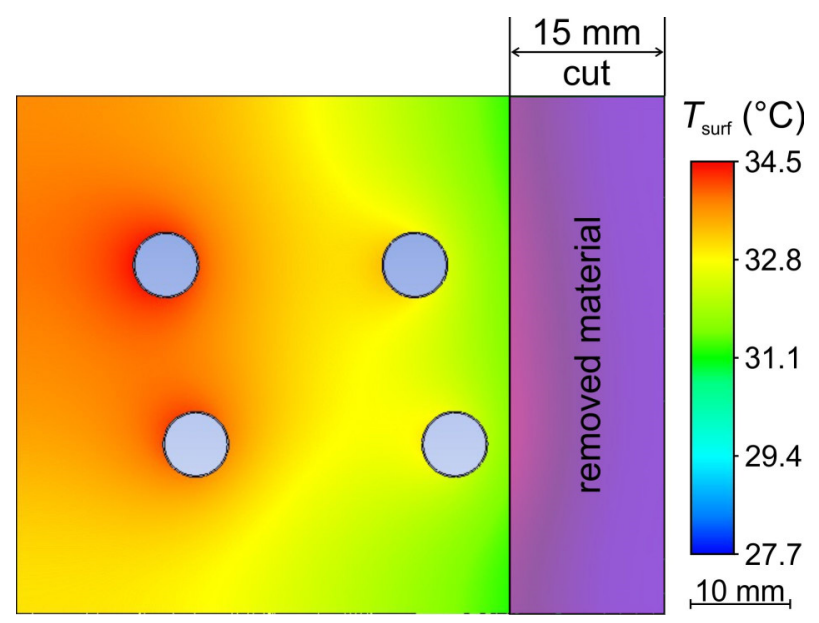

Figure 21. Temperature profile of a stock fin at the heating power of $100 \mathrm{~W}$ with indicated cut material.

(a)

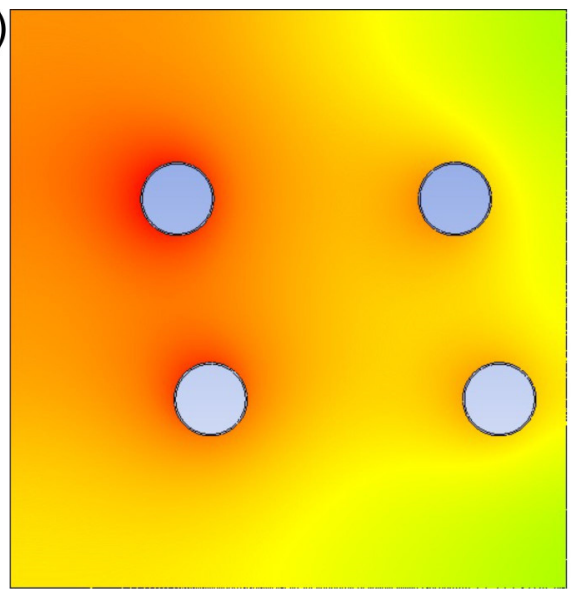

(b)

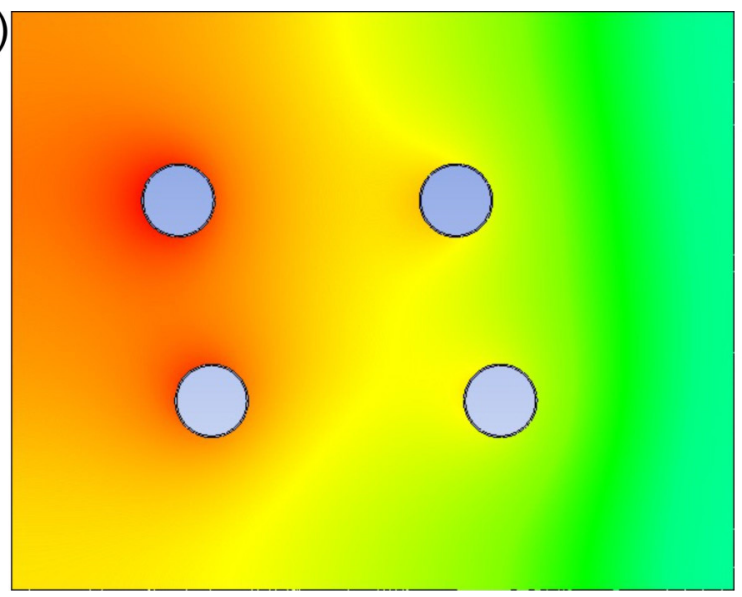

$T_{\text {surf }}\left({ }^{\circ} \mathrm{C}\right)$

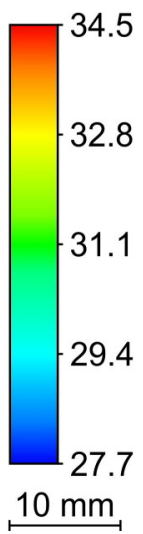

Figure 22. Temperature distribution for the case of heating power of $100 \mathrm{~W}$ on the a) optimized and b) stock fin.

After the fin optimization procedure, the average value of the fin effectiveness for all three heating powers are slightly lower compared to the stock fin (5.68 and 5.75, respectively), as shown in Fig. 20. The relative difference of both values of approx. $1 \%$ shows a possible numeric error, since the exact same amount of heat is dissipated through the optimized fin as in the case of a stock fin. Once again, the fin effectiveness has been proven to be invariant with heating power. Fin efficiencies of the optimized fin, on the other hand, show a significant increase 
compared to the stock fin for all three heating powers (with average values of $79 \% \mathrm{vs.} 64 \%$, respectively, shown in Fig. 20).

The thermal performance optimization methodology, based on the fin effectiveness and fin efficiency, presents a useful mechanism for fin optimization. It has already been shown as a highly promising approach by several authors. For instance, a numerical investigation using the local fin efficiency has already been proven as a feasible way of plate-fin HX performance assessment [41], while both, the fin efficiency and fin effectiveness were used as leading parameters in numerical investigation of printed circuit HX [42]. By using this methodology, it is possible to perform a large set of simulations and sensitivity analyses, which can aid the HX design with lower R\&D time investment, while at the same time high energy and material efficiency could be achieved. In the case of a PC CPU cooling system, we proved that fin optimization, based on numeric simulations, can yield significantly higher fin efficiencies (23\% increase), while at the same time the weight of the fins was reduced by $30 \%$ (approx. $88.5 \mathrm{~g}$ for the entire stack of 56 fins). The main results of the simulations on the stock and optimized fin are summarized in Table 3.

Table 3. Comparison of the stock and the optimized fin.

\begin{tabular}{|c|c|c|c|}
\hline Parameter & Stock fin & Optimized fin & Difference \\
\hline Fin width (mm) & 65 & 50 & $-15 \mathrm{~mm}(-12 \%)$ \\
\hline Combined weight of fins (g) & 115 & 88.5 & $-26.5 \mathrm{~g}(-30 \%)$ \\
\hline Average fin temperature at $\mathbf{1 0 0} \mathbf{~ W}\left({ }^{\circ} \mathbf{C}\right)$ & 32.7 & 33.4 & $+0.7 \mathrm{~K}$ \\
\hline Average fin effectiveness (/) & 5.75 & 5.68 & $-0.07(-1.2 \%)$ \\
\hline Average fin efficiency (\%) & 64 & 79 & $+15 \%(+23 \%)$ \\
\hline
\end{tabular}

One of the main benefits of using the proposed methodology by the means of numerical simulations is to perform a coupled thermo-hydraulic optimization. Using the proposed methodology, the heat transfer across the whole surface area of the fin can be optimized. While increasing the fin density per unit length could provide larger heat transfer area and reduce the HX size, the smaller gap between the fins could lead to an increased pressure drop and lower airflow, which would in turn lower the average value of the heat transfer coefficient. 


\section{Conclusions}

The measured performance of the tested HP-based CPU coolers is largely invariant to the orientation within the range of air volumetric flow rates provided by the stock fan. The major thermal resistance is attributed to the air-side of the cooler, obscuring the changes in the thermal resistance of the HP due to different inclination angles. Even during passive operation without forced airflow, the variations in the performance can be attributed chiefly to the varying intensity of natural convection on horizontal/vertical fins. The measured thermal resistance of the used coolers (operating under forced convection using stock fans) ranged between $0.14-0.19 \mathrm{~K} \mathrm{~W}^{-1}$ at low heat fluxes (i.e., low heating powers) and between $0.11-0.12 \mathrm{~K} \mathrm{~W}^{-1}$ at high heating powers. Only when a substantially larger air volumetric flow rate was provided, a difference between the $0^{\circ}$ and $90^{\circ}$ orientation could be observed with the latter orientation exhibiting higher cooling performance, which is attributed to a more favorable heat pipe orientation. Overall, a fourfold increase in the airflow resulted in a relatively small increase of the cooling performance of the cooler with a recorded thermal resistance of $0.074 \mathrm{~K} \mathrm{~W}^{-1}$ at the highest measured heat flux.

The second part of this study presents a novel CFD-based performance optimization methodology, which demonstrates numerical simulation-based calculation of the fin efficiency and fin effectiveness for the geometry of or similar to the finned part of a HP-based CPU cooler. Results of numerical simulations were validated against experimental measurements with an average difference of $1.0 \mathrm{~K}$. The use of the proposed methodology is demonstrated through the optimization of the fin geometry, where numerical simulations on a smaller fin, from which some material deemed unnecessary was removed, show that in just a single optimization step, the fin efficiency can easily be increased by a considerable margin of $23 \%$ (64\% vs. $79 \%$ for the stock and the optimized fin, respectively). Utilizing this methodology, it is possible to not only save monetary investment and reduce the development time, but also reduce the weight of finned, HP-based coolers by conducting optimization though a number of numerical simulations without building physical prototypes. 


\section{Acknowledgements}

The authors acknowledge the financial support from the state budget by the Slovenian Research Agency (Program/Project Nr. P2-0223). 


\section{References}

[1] G.E. Moore, Cramming more components onto integrated circuits, Electronics. 38 (1965) 114. doi:10.1109/N-SSC.2006.4785860.

[2] Y. Wang, B. Wang, K. Zhu, H. Li, W. He, S. Liu, Energy saving potential of using heat pipes for CPU cooling, Appl. Therm. Eng. (2018). doi:10.1016/j.applthermaleng.2018.07.132.

[3] K.S. Kim, M.H. Won, J.W. Kim, B.J. Back, Heat pipe cooling technology for desktop PC CPU, Appl. Therm. Eng. 23 (2003) 1137-1144. doi:10.1016/S1359-4311(03)000449.

[4] B. Agostini, M. Fabbri, J.E. Park, L. Wojtan, J.R. Thome, B. Michel, State of the art of high heat flux cooling technologies, Heat Transf. Eng. 28 (2007) 258-281. doi:10.1080/01457630601117799.

[5] A.F. Ali, M.S. El-Genk, Spreaders for immersion nucleate boiling cooling of a computer chip with a central hot spot, Energy Convers. Manag. 53 (2012) 259-267. doi:10.1016/j.enconman.2011.09.007.

[6] M.S. El-Genk, Immersion cooling nucleate boiling of high power computer chips, Energy Convers. Manag. 53 (2012) 205-218. doi:10.1016/j.enconman.2011.08.008.

[7] P. Gregorčič, M. Zupančič, I. Golobič, Scalable Surface Microstructuring by a Fiber Laser for Controlled Nucleate Boiling Performance of High- and Low-Surface-Tension Fluids, Sci. Rep. 8 (2018). doi:10.1038/s41598-018-25843-5.

[8] J. Voglar, P. Gregorčič, M. Zupančič, I. Golobič, Boiling performance on surfaces with capillary-length-spaced one- and two-dimensional laser-textured patterns, Int. J. Heat Mass Transf. 127 (2018) 1188-1196. doi:10.1016/j.ijheatmasstransfer.2018.07.056.

[9] P. Zakšek, M. Zupančič, P. Gregorčič, I. Golobič, Investigation of Nucleate Pool Boiling of Saturated Pure Liquids and Ethanol-Water Mixtures on Smooth and Laser-Textured Surfaces, Nanoscale Microscale Thermophys. Eng. 24 (2020) 29-42. doi:10.1080/15567265.2019.1689590.

[10] A. Sitar, M. Može, M. Crivellari, J. Schille, I. Golobič, Nucleate pool boiling heat transfer on etched and laser structured silicon surfaces, Int. J. Heat Mass Transf. 147 (2020) 118956. doi:10.1016/j.ijheatmasstransfer.2019.118956.

[11] M. Alhuyi Nazari, M.H. Ahmadi, R. Ghasempour, M.B. Shafii, O. Mahian, S. Kalogirou, S. Wongwises, A review on pulsating heat pipes: From solar to cryogenic applications, Appl. Energy. 222 (2018) 475-484. doi:10.1016/J.APENERGY.2018.04.020.

[12] Y.W. Chang, C.H. Cheng, J.C. Wang, S.L. Chen, Heat pipe for cooling of electronic equipment, Energy Convers. Manag. (2008). doi:10.1016/j.enconman.2008.05.002.

[13] J.C. Wang, Superposition method to investigate the thermal performance of heat sink with embedded heat pipes, Int. Commun. Heat Mass Transf. (2009). doi:10.1016/j.icheatmasstransfer.2009.04.008. 
[14] T.S. Liang, Y.M. Hung, Experimental investigation on the thermal performance and optimization of heat sink with U-shape heat pipes, Energy Convers. Manag. (2010). doi:10.1016/j.enconman.2010.03.003.

[15] M.H.A. Elnaggar, M.Z. Abdullah, M. Abdul Mujeebu, Experimental analysis and FEM simulation of finned U-shape multi heat pipe for desktop PC cooling, Energy Convers. Manag. 52 (2011) 2937-2944. doi:10.1016/j.enconman.2011.03.001.

[16] J. Choi, M. Jeong, J. Yoo, M. Seo, A new CPU cooler design based on an active cooling heatsink combined with heat pipes, Appl. Therm. Eng. 44 (2012) 50-56. doi:10.1016/j.applthermaleng.2012.03.027.

[17] M. Ghanbarpour, N. Nikkam, R. Khodabandeh, M.S. Toprak, Thermal performance of inclined screen mesh heat pipes using silver nanofluids, Int. Commun. Heat Mass Transf. 67 (2015) 14-20. doi:10.1016/j.icheatmasstransfer.2015.06.009.

[18] W.I.A. Aly, M.A. Elbalshouny, H.M. Abd El-Hameed, M. Fatouh, Thermal performance evaluation of a helically-micro-grooved heat pipe working with water and aqueous Al2O3 nanofluid at different inclination angle and filling ratio, Appl. Therm. Eng. (2017). doi:10.1016/j.applthermaleng.2016.08.130.

[19] M. Hu, R. Zheng, G. Pei, Y. Wang, J. Li, J. Ji, Experimental study of the effect of inclination angle on the thermal performance of heat pipe photovoltaic/thermal (PV/T) systems with wickless heat pipe and wire-meshed heat pipe, Appl. Therm. Eng. (2016). doi:10.1016/j.applthermaleng.2016.06.003.

[20] H.R. Goshayeshi, M. Goodarzi, M.R. Safaei, M. Dahari, Experimental study on the effect of inclination angle on heat transfer enhancement of a ferrofluid in a closed loop oscillating heat pipe under magnetic field, Exp. Therm. Fluid Sci. 74 (2016) 265-270. doi:10.1016/J.EXPTHERMFLUSCI.2016.01.003.

[21] C. Wang, L. Zhang, X. Liu, S. Tang, S. Qiu, G.H. Su, Experimental study on startup performance of high temperature potassium heat pipe at different inclination angles and input powers for nuclear reactor application, Ann. Nucl. Energy. 136 (2020) 107051. doi:10.1016/J.ANUCENE.2019.107051.

[22] A.C. Gurses, C. Cannistraro, L. Tezcan, The inclination effect on the performance of water-filled heat pipes, Renew. Energy. 1 (1991) 667-674. doi:10.1016/09601481(91)90012-E.

[23] C.K. Loh, E. Harris, D.J. Chou, Comparative study of heat pipes performances in different orientations, in: Annu. IEEE Semicond. Therm. Meas. Manag. Symp., 2005: pp. 191-195. doi:10.1109/stherm.2005.1412178.

[24] T. Yousefi, S.A. Mousavi, B. Farahbakhsh, M.Z. Saghir, Experimental investigation on the performance of CPU coolers: Effect of heat pipe inclination angle and the use of nanofluids, Microelectron. Reliab. 53 (2013) 1954-1961. doi:10.1016/j.microrel.2013.06.012.

[25] S.H. Moon, G. Hwang, H.G. Yun, T.G. Choy, Y. Kang, Improving thermal performance of miniature heat pipe for notebook PC cooling, Microelectron. Reliab. (2002). doi:10.1016/S0026-2714(01)00226-8. 
[26] X. Ji, H. Li, J. Xu, Y. Huang, Integrated flat heat pipe with a porous network wick for high-heat-flux electronic devices, Exp. Therm. Fluid Sci. (2017). doi:10.1016/j.expthermflusci.2017.03.008.

[27] E. Ozturk, I. Tari, Forced Air Cooling of CPUs With Heat Sinks: A Numerical Study, IEEE Trans. Components Packag. Technol. 31 (2008) 650-660. doi:10.1109/TCAPT.2008.2001840.

[28] J. Choi, M. Jeong, Compact, lightweight, and highly efficient circular heat sink design for high-end PCs, Appl. Therm. Eng. (2016). doi:10.1016/j.applthermaleng.2015.09.096.

[29] VDI e. V., VDI Heat Atlas, Springer-Verlag Berlin Heidelberg, 2010.

[30] T.L. Bergman, F.P. Incropera, D.P. DeWitt, A.S. Lavine, Fundamentals of Heat and Mass Transfer, Wiley, 2011.

[31] W. Siddique, I. V. Shevchuk, L. El-Gabry, N.B. Hushmandi, T.H. Fransson, On flow structure, heat transfer and pressure drop in varying aspect ratio two-pass rectangular channel with ribs at 45, Heat Mass Transf. Und Stoffuebertragung. 49 (2013) 679-694. doi:10.1007/s00231-013-1111-5.

[32] W. Siddique, L. El-Gabry, I. V. Shevchuk, N.B. Hushmandi, T.H. Fransson, Flow structure, heat transfer and pressure drop in varying aspect ratio two-pass rectangular smooth channels, Heat Mass Transf. Und Stoffuebertragung. 48 (2012) 735-748. doi:10.1007/s00231-011-0926-1.

[33] R.D. Blevins, Flow-Induced Vibration, Second Edi, Van Nostrand Reinhold Company, Inc., 1990.

[34] A. Fasquelle, J. Pellé, S. Harmand, I. V. Shevchuk, Numerical study of convective heat transfer enhancement in a pipe rotating around a parallel axis, J. Heat Transfer. 136 (2014). doi:10.1115/1.4025642.

[35] J.A. Almendros-Ibáñez, J.F. Belmonte, A.E. Molina, Fins with a prescribed temperature at the tip: Efficiency and effectiveness expressions, Appl. Therm. Eng. (2015). doi:10.1016/j.applthermaleng.2015.08.044.

[36] R.H. Chen, L. Kuo, C.M. Lai, The influence of longitudinal vibrations on the heat transfer performance of inclined heat pipes, Adv. Mech. Eng. 7 (2015) 1-13. doi:10.1177/1687814015568940.

[37] J. Raghuram, K.V.N.K. Phani Kumar, G. V Khiran, K. Snehith, S.B. Prakash, Thermal performance of a selected heat pipe at different tilt angles, IOP Conf. Ser. Mater. Sci. Eng. 225 (2017) 012043. doi:10.1088/1757-899X/225/1/012043.

[38] F. Idrus, N. Mohamad, R. Zailani, W. Wisnoe, M.Z. Abdullah, Thermal Performance of a Cylindrical Heat Pipe for Different Heat Inputs and Inclination Angles, Appl. Mech. Mater. 661 (2014) 148-153. doi:10.4028/www.scientific.net/AMM.661.148. 
[39] G. Kumaresan, S. Venkatachalapathy, A Review on Heat Transfer Enhancement Studies of Heat Pipes Using Nanofluids, Front. Heat Pipes. 3 (2013) 1-8. doi:10.5098/fhp.v3.4.3001.

[40] J.C. Wang, H.S. Huang, S.L. Chen, Experimental investigations of thermal resistance of a heat sink with horizontal embedded heat pipes, Int. Commun. Heat Mass Transf. 34 (2007) 958-970. doi:10.1016/j.icheatmasstransfer.2007.03.015.

[41] H. Yang, Y. Li, Y. Yang, Y. Zhu, J. Wen, Effect of surface efficiency on the thermal design of plate-fin heat exchangers with passages stack arrangement, Int. J. Heat Mass Transf. (2019). doi:10.1016/j.ijheatmasstransfer.2019.118494.

[42] S. Liu, Y. Huang, J. Wang, Theoretical and numerical investigation on the fin effectiveness and the fin efficiency of printed circuit heat exchanger with straight channels, Int. J. Therm. Sci. (2018). doi:10.1016/j.ijthermalsci.2018.06.029. 


\section{List of figures}

Figure 1. Schematic depiction of the experimental setup; no CPU cooler mounting parts are shown for improved clarity.

Figure 2. Renders of the 3-D model showing the heater block mounts (a), heater block cross-section (b) and the experimental setup in two possible orientations (c).

Figure 3. Data acquisition setup.

Figure 4. Experimentally obtained correlation between the heating block superheat, defined as $T_{\text {block }}-T_{\text {amb }}$, and conductive heat losses of the experimental setup.

Figure 5. "Cooler 1" (a) and "Cooler 2" (b).

Figure 6. Locations of temperature measurements on cooler's fin (a) and on the cooler's heat pipes (b). Dimensions are in millimeters and the drawing is not to scale.

Figure 7. Geometry of the fins and the inter-fin channel of the HP-based CPU cooler used in CFD simulations.

Figure 8. Calculation domain of the CFD simulation and the corresponding boundary conditions (a) and a crosssection of the inter-fin space (b).

Figure 9. Cooling characteristics of "Cooler 1" in different orientations with the fan not operating.

Figure 10. Cooling characteristics of "Cooler 1" in different orientations when operating with the fan at full speed.

Figure 11. Cooling characteristics of "Cooler 1" in different orientations when operating under the influence of a large external axial blower.

Figure 12. Cooling characteristics of "Cooler 2" in different orientations when operating with the fan at full speed.

Figure 13. Comparison of the cooling characteristics of "Cooler 1" in different orientations when operating with the fan either turned off or at full speed or under the influence of a large external blower

Figure 14. Comparison of the cooling characteristics of "Cooler 1" and "Cooler 2" in different orientations when operating with the fan at full speed.

Figure 15. Temperature distribution across a fin at $100 \mathrm{~W}$ using the k- $\varepsilon$ EWT model and either a fine (a), coarse (b) or medium density mesh (c). Temperature distribution across a fin at $100 \mathrm{~W}$ using a coarse mesh and either

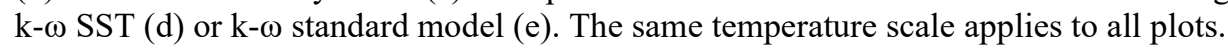

Figure 16. Comparison of surface-averaged temperatures of the bottom and the top fin and the volume-averaged temperature of the fluid between the fins for different mesh densities, heating powers and turbulence models (a) and comparison of standard deviation of these temperatures (b). The same legend applies to both plots.

Figure 17. Eight-point comparison of the temperature of the fluid in the middle of the inter-fin channel (a) and the temperature of the fin surface (b); the same legend applies to both plots. Boxplot showing the validation of simulation results against measured temperatures for different turbulence models on a coarse mesh at $100 \mathrm{~W}$ (c).

Figure 18. Streamlines of airflow in the inter-fin space (a) and the temperature distribution across the fin at $100 \mathrm{~W}$ (b).

Figure 19. Boxplot comparison of differences between predicted temperatures (from numerical simulation) and measured temperatures. 
Figure 20. Fin effectiveness and fin efficiency of the stock and optimized fin at different heating powers.

Figure 21. Temperature profile of a stock fin at the heating power of $100 \mathrm{~W}$ with indicated cut material.

Figure 22. Temperature distribution for the case of heating power of $100 \mathrm{~W}$ on the a) optimized and b) stock fin. 


\section{List of tables}

Table 1. CPU cooler geometry and properties.

Table 2. Comparison of thermal resistance values of finned heat sinks with heat pipes reported by other authors.

Table 3. Comparison of the stock and the optimized fin. 